\title{
RETIREMENT WEALTH ACCUMULATION AND DECUMULATION: NEW DEVELOPMENTS AND OUTSTANDING OPPORTUNITIES
}

\author{
Olivia S. Mitchell \\ James F. Moore
}

Working Paper 6178

http://www.nber.org/papers/w6178

\author{
NATIONAL BUREAU OF ECONOMIC RESEARCH \\ 1050 Massachusetts Avenue \\ Cambridge, MA 02138 \\ September 1997
}

Financial support for this research project was provided by KPMG and the Wharton School's Financial Institutions Center. The authors are grateful for comments from Anthony Santomero and Jill Goldman. Opinions are those of the authors and not those of the institutions with which they are affiliated, or the National Bureau of Economic Research. This paper is part of NBER's research programs in Aging and Labor Studies.

(C) 1997 by Olivia S. Mitchell and James F. Moore. All rights reserved. Short sections of text, not to exceed two paragraphs, may be quoted without explicit permission provided that full credit, including $\mathbb{C}$ notice, is given to the source. 
Retirement Wealth Accumulation and Decumulation:

New Developments and Outstanding Opportunities

Olivia S. Mitchell and James F. Moore

NBER Working Paper No. 6178

September 1997

JEL Nos. H55, O16, J26, G23

Aging and Labor Studies

\begin{abstract}
Analysts have raised questions about current workers' ability and inclination to save enough for retirement. This issue is of obvious policy interest given the current debate over reforming national retirement income programs. This paper explores the implications of recent research regarding retirement wealth accumulation and decumulation for this debate. Our goal is to identify problems and opportunities in the area of preparedness for retirement.
\end{abstract}

Olivia S. Mitchell

Department of Insurance and Risk Management

The Wharton School

University of Pennsylvania 3641 Locust Walk

Philadelphia, PA 19 104-62 18

and NBER

mitchelo@wharton.upenn.edu
James F. Moore

Department of Insurance and Risk Management

The Wharton School

University of Pennsylvania

3641 Locust Walk

Philadelphia, PA 19 104-62 18 
Retirement Wealth Accumulation and Decumulation:

New Developments and Outstanding Opportunities

Olivia S. Mitchell and James F. Moore

NBER Working Paper No. 6178

September 1997

JEL Nos. H55, O16, J26, G23

Aging and Labor Studies

\begin{abstract}
Analysts have raised questions about current workers' ability and inclination to save enough for retirement. This issue is of obvious policy interest given the current debate over reforming national retirement income programs. This paper explores the implications of recent research regarding retirement wealth accumulation and decumulation for this debate. Our goal is to identify problems and opportunities in the area of preparedness for retirement.
\end{abstract}

Olivia S. Mitchell

Department of Insurance and Risk Management

The Wharton School

University of Pennsylvania

3641 Locust Walk

Philadelphia, PA 19 104-62 18

and NBER

mitchelo@wharton.upenn.edu
James F. Moore

Department of Insurance and Risk Management

The Wharton School

University of Pennsylvania

3641 Locust Walk

Philadelphia, PA 19 104-62 18 


\section{Retirement Wealth Accumulation and Decumulation: New Developments and Outstanding Opportunities}

This paper has three goals. The first is to describe and evaluate patterns in retirement asset accumulation in order to offer an assessment of the claim that Americans do a poor job of preparing for retirement. The second is to evaluate patterns of retirement asset decumulation, in order to determine whether the available financial and other tools are available to achieve satisfactory consumption during retirement. Finally, given what we have found, we outline approaches to assist in improving the targeting and management of retirement accumulation and decumulation paths.

Our discussion begins by describing patterns of wealth accumulation among American families, drawing from a valuable new data set on saving patterns for a nationally representative set of older households. We then compare the actual accumulations found in the data to a range of saving benchmarks to identify the extent of saving shortfalls. Next, we examine which incentives could enhance the rate of retirement asset accumulation. The discussion goes on to explore asset allocation patterns of working people saving for retirement. We compare a range of financial benchmarks with data from recent surveys on pension asset allocation information. In the third substantive section of the paper, we describe and evaluate the process of retirement asset decumulation. Targets offered by the financial community are again contrasted with behavior, and factors influencing the retirement decumulation process described. In the final section of this paper we gather our conclusions.

\section{Wealth Accumulation on the Verge of Retirement}

In order to decide whether people are saving enough for retirement we require evidence on saving patterns of workers as they age, as well as on their retirement income needs. In this section we explore a range of sources on patterns of retirement wealth accumulation, and ask whether actual saving patterns are likely to be enough to protect retiree economic security.

It is important to start out with a statement of fact - namely, it is extraordinarily difficult to find out about people's saving rates and wealth levels. Indeed it is only recently that the inherently imperfect exercise of measuring wealth has become easier because of newly devised and quite elaborate survey instruments following the same people over time.

One problem in gathering wealth information is that a snapshot of assets at a moment in time conceals fluctuations in asset values over time (e.g. stock prices, real estate values). In fact, measuring wealth will always involve making judgments about a moving target. Another problem is that wealth studies suffer from respondent recall - people have a hard time remembering what assets they own and often do not know the values of these assets. This is particularly a concern 
with owner occupied housing, for example, where the housing value is only imperfectly known unless the owner has purchased the house recently. A related consideration is that respondents are sometimes unwilling to report wealth to survey interviewers, a reluctance thought to be most concentrated among the wealthiest segment of society.

For all these reasons researchers have concluded that new data on wealth must be developed, and a range of such surveys has begun to be fielded with which experts can begin to correct some of the deficiencies of prior work. It appears that the effort and expense of these new nationally representative surveys is worthwhile, particularly because careful design of wealth questions in datasets like the Health and Retirement Study (HRS) has produced much higher levels of household wealth than those identified in previous studies (Smith 1995). These advances have been accomplished by recognizing that some types of wealth are relatively easy to recall but other types are not readily reportable. Thus for instance a respondent may remember his checking account balance, but he may not know the value of his entire pension or social security retirement annuity. Therefore another advance in data collection has been researchers' capability to merge with household members' their social security earnings records as well as material taken from employer-side pension records. This complex datafile merge is only available under restricted access circumstances to protect confidentiality of respondents. ${ }^{1}$ Nonetheless these new files produce more reliable and better quality wealth data than have ever been available in the past.

There is no single "gold standard" for measuring what is meant by wealth. Here we define net financial wealth to be the sum of funds held in stocks, bonds, checking and saving accounts, money market accumulations, business capital, and individual retirement accounts (e.g. IRA's and Keoghs). Some studies focus only on this concept on the argument that it is the most liquid form of wealth holdings. A second commonly reported measure is net financial wealth plus housing or accessible wealth, that adds to the financial wealth total an estimate of net housing equity. The third and most comprehensive wealth measure, termed here total net wealth, adds to the foregoing a calculated measure of public and private retirement pensions. As will be explained below, this last measure requires the inclusion of pension accumulations in defined contribution pension plans (including 401(kp ans), and also necessitates the valuation of annuities from defined benefit and social security pensions. Each of these terms will be examined in our assessment of wealth levels and savings rates, below.

\section{A. The Facts About Retirement Wealth}

The Health and Retirement Study (HRS) affords an excellent opportunity for exploring asset accumulation patterns of those near retirement. This study sampled more than 7600 households in 1992 where at least one family member was between the ages of 51 and 61 . Unlike most other

\footnotetext{
${ }^{1}$ See Mitchell, Olson, Steinmeier (1996) and Gustman, Mitchell, Samwick, and Steimneier (1997).
} 
cross-sectional household surveys used in the past to study asset accumulation, consumption patterns, and saving behavior, the HRS follows these original households through time, reinterviewing them every two years. In the future, this panel will provide a fertile data set for studying how households accumulate assets preceding retirement, how they decumulate assets in retirement, and how they manage bequests.

\section{How Much Retirement Wealth do People Have?}

One recent analysis of the first year of HRS data was undertaken by Gustman, Mitchell, Samwick, and Steinmeier (GMSS 1997), who explored wealth holdings of this cohort of people on the verge of retirement. A summary of their results appears in Table I.A. 1. All data are weighted to be representative of the US population in this age bracket, and dollar figures are presented in 1992 dollars. Mean values, the average for the median ten percent of households, and averages for those households reporting each wealth source are presented along with the percentages of total wealth each asset class represents. Wealth in that study is divided into three categories?

- Financial wealth, which includes business assets, financial assets (such as stocks, bonds, and bank accounts less outstanding debt), dedicated retirement assets including IRA and Keogh Accounts, and miscellaneous other fmancial;

- Net home equity for homeowners; and

*Retirement wealth, equal to the actuarial present value of future social security retirement and survivor benefits, retirement pension benefits, and private retiree health insurance. 3

The evidence shows that the average HRS household has just under half a million dollars in total wealth. Total wealth for the median ten percent of households (i.e. the group between the 45th and 55th percentile) is almost $\$ 340,000$, slightly more than two-thirds of the mean for the entire sample. The fact that the median is below the mean emphasizes the skewness of the wealth distribution, a point to be discussed in greater depth below.

The composition of total wealth also differs for the mean and median households. For the average HRS household, retirement wealth comprises slightly more than half of total wealth (52\%), financial wealth approximately one-third of total wealth (32\%), and the value of housing makes up the remaining fraction (16\%). By contrast, for the median household, retirement wealth comprises almost two-thirds (63\%) of total assets, housing accounts for a fifth (20\%), leaving financial assets with the final $17 \%$ of total wealth. Social security wealth alone makes up $43 \%$ of total wealth for households near the median total wealth, for total of about $\$ 145,000$. For the household at the

\footnotetext{
2 Throughout this study we exclude the value of Medicare in retirement wealth.

3 Social security benefits include retirement benefits as well as survivor benefits; these figures are computed using the intermediate assumptions used by the Social Security Administration to assess its funding status. For further detail on construction of these data see Mitchell, Olson, and Steinmeier (1996) and GMSS (1997).
} 
sample mean, social security wealth represents $27 \%$ of the total, or about $\$ 134,000$ in present value terms.

It is interesting to note that while most asset types have higher dollar values for the mean than for the median household, the reverse holds for social security. This is in large part due to the redistributive nature of social security benefits.

The two final columns of Table I.A. 1 report the fraction of HRS households that holds wealth in each of the specified categories, along with average values for those households with nonzero holdings. Coverage by social security is near universal among HRS participants, with 96\% of households expecting some benefit from that system. A significant majority of sampled households also holds some financial assets (88\%), and most (80\%) own their primary residence. Slightly under two-thirds of the sample expects an employer provided pension, similar to overall coverage levels for this age bracket in the United States. Business assets are held by only one third of the sample (32\%), but their average value, around $\$ 250,000$, is quite large for those households holding them.

Only $42 \%$ of HRS households - on the verge of retirement, it will be recalled - have any personal dedicated retirement assets. The average value of these assets among those with positive holdings is $\$ 47,000$. People's failure to take advantage of the tax advantages inherent in targeted saving programs might be explained by household lack of understanding of the availability of these programs, or perhaps because they do not value retirement saving. Alternatively, households may choose to hold assets in non-tax-favored categories because of the increased flexibility and lack of potential penalties for early withdrawal. The efficacy of dedicated retirement saving programs is discussed in more detail in Section I.C., below.

More detail on the distribution of HRS assets appears in Table IA.2 and Figure I.A. 1. Averages are given for the two extreme ventiles at each end of the total wealth distribution (0-5\%, $5-10 \%$, and $90-95 \%, 95-100 \%$ ) as well as for larger subgroups in the interior of the wealth distribution. Averages are also presented for the entire sample as well as for the median $10 \%$ of households. The final row of the Table presents the ratio of the average values for the $90-95 \%$ ventile to that of the $5-10 \%$ ventile. Values are presented for total net wealth, pension wealth, social security, home value, and net financial wealth. A graphical view of these data appears in Figure I.A. 1, where the total height of each bar represents total net wealth by distribution grouping. Components of wealth are represented in each bar by the height of each subsection.

The evidence further substantiates the above-noted inequality in the distribution of wealth. Households in the top $10 \%$ of the wealth distribution have total wealth in excess of $\$ 1 \mathrm{M}$, and would seem to be quite well positioned for retirement. A very different pattern characterizes people at the other end of the wealth distribution. Those in the second ventile have on average slightly over $\$ 60,000$ in net wealth. Households in the poorest ventile average less than $\$ 10,000$ in total net 
worth. If the present value of future social security and pension benefits were subtracted from the total, households in the bottom ventile of the wealth distribution have substantially negative net worth.

Another way to describe the heterogeneity in wealth is to compute the ratio of wealth for the $90-95 \%$ ventile relative to that of the $5-10 \%$ ventile. 4 This ratio, effectively a weighted average of the various component parts for total wealth, is nearly 19. With the exception of social security, the ratios for the other component pieces exceed those for total wealth. The ratio is largest for pension wealth (310) and net financial wealth (222), indicating that these are the most unequally distributed asset classes. The ratio for social security, 3.6, is much lower. This is a function of the social security benefit formula in which benefits are a concave function of average past earnings, giving more weight to the first dollars earned and less weight to higher earnings levels. There is also a limit on the level of earnings used to calculate benefits, thereby giving a maximum possible level of benefits (there are also family caps as well).

Net financial wealth gives a picture of the assets most readily usable for retirement consumption. Along with pensions, this is the wealth category that is most highly skewed, a result

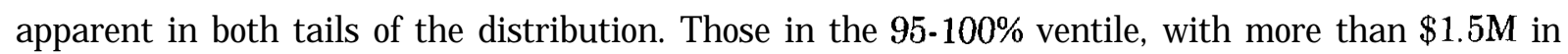
net financial wealth, have nearly four times as much as those in the 90-95\% ventile. At the other end of the distribution, those in the poorest ventile have negative net financial wealth and are in debt on the doorstep of retirement. Those in the next ventile up are similarly destitute, having an average of less than $\$ 2,000$ in net financial wealth - a scant three percent of total wealth.

A question arises as to whether wealth holdings are associated with various potential explanatory factors. To this end, Table I.A.3 presents wealth by education, marital status, race of the households primary respondent, and the households total household income in 1992.

Education level is broken down into four categories based on the highest level of educational attainment by the households primary HRS interviewee. The categories are: less than a high school degree, high school diploma or equivalent (GED), a bachelor's degree, and an advanced degree (e.g. master 's degree, PhD., law degree, or medical degree). Not surprisingly, levels of both financial wealth and financial wealth plus housing are strongly increasing in education. Median values for those without a high school diploma are $\$ 18,000$ for financial wealth and $\$ 61,050$ when the value of housing is added. For those with advanced degrees, the corresponding median values are $\$ 139,000$ and $\$ 231,000$, respectively.

The data also show that the share of wealth held in housing declines as education increases. Housing value represents approximately $70 \%$ of net financial wealth plus housing for those without

4 These ventiles are used instead of the first and twentieth ventile because for some wealth categories, specifically net financial wealth, the poorest ventile has negative wealth values. Also, 
a high school degrees, while for the other three groups, housing represents approximately $60 \%$, $53 \%$, and $40 \%$ (at the median). It is interesting to note that although those with advanced degrees hold more financial wealth than those with bachelors degrees, they hold less housing wealth on an absolute basis at the median. This may represent either a conscious choice to hold wealth in assets that are more liquid than housing, or it might indicate that those who pursued education deferred purchasing homes.

Splitting the sample by marital status reveals substantial differences for married couples, single males, and single females (where single includes widowed, divorced, separated, and never married individuals and their dependents). The median married couple has approximately three times the financial wealth of the median single male, and eight times the financial wealth of the single female household. Housing makes up about the same fraction of accessible financial wealth (excluding pensions, social security, and retiree health insurance) for married couples and single males, approximately 54\% and 53\% respectively, but housing is nearly $80 \%$ of accessible wealth for single female-headed households. Single females also hold more housing wealth on an absolute basis, although they hold less accessible wealth than their male counterparts. This may in part be attributable to the split of assets in divorce.

A third wealth breakdown is by race. The HRS intentionally oversamples Black and Hispanic households to provide a more accurate picture of the behavior of these minority households.5 The evidence shows that the median HRS Black and Hispanic household on the verge of retirement, has only $\$ 5000$ in financial wealth. Whites hold substantially more wealth than either Blacks or Hispanics, with approximately 11 times more financial wealth and approximately four times as much when housing is included. For all racial groupings, housing wealth comprises more than half of wealth at the median. Its importance is even greater for Black and Hispanic households, where housing equity represents the vast majority of accessible wealth.

Patterns seen in household income mirror those observed in the wealth breakdowns. Net financial wealth is far more unequally distributed across income than housing wealth: the ratio of the median net financial wealth values for the highest to the lowest income quintile is approximately 55, while for housing wealth the corresponding ratio is about 7.4. This reiterates the substantial heterogeneity of wealth accumulation outside of home ownership.

Looking within each income quintile, we again find that the means are substantially larger than the medians. This confirms substantial skewness in the distribution of wealth even after controlling on respondents' current income. This skewness is most pronounced for the lowest income quintile, where mean wealth is 4.7 times greater than the median. Some of the households

average values for the wealthiest ventile may reflect the influence of a few extreme data pointss and may therefore yield an upwardly biased result. 
at the very lowest end of the income distribution are probably temporarily experiencing low income due to unemployment and disability, and in addition may include early retirees not yet eligible for social security benefits. Conversely, the wide range of wealth levels observed even for those with low current income suggests that saving and wealth accumulation is feasible for some at low income levels.

A subject of considerable debate in the economics literature is whether the value of owneroccupied housing should be included when assessing the sufficiency of assets for retirement. Some analysts argue that housing wealth should not be taken into account, since retirees are understandably reluctant to move from the houses they lived in while working Venti and Wise 1991). They point out that this wealth is often not used to supplement consumption, instead providing an emergency contingency fund for those who may need it, and serving as a bequest to the heirs of those who do not. They also argue that high transaction costs associated with moving make accessing the housing equity quite expensive.

By contrast, those who argue that people's housing values should be counted in retirement wealth point out that this is the single largest source of many peoples' wealth, and it can be used to increase consumption. They also point to the rapid growth in second mortgages and the potential for growth in the reverse mortgage market. 6 Their argument centers on the role of housing equity as collateral - retirees do not need to leave their homes to make use their value.

Another way to think about how to include housing wealth as a component of retirement assets involves decomposing mortgage payments into two parts - an investment component and a consumption component. The investment component recognizes the purchase of the house as a speculative investment in a tangible asset. A homeowner can subsequently sell the house and reap the gains (or losses) of its change in value. Since it is a durable store of value, it also has use as collateral. The consumption component represents what the homeowner would pay for housing services, or for the non-homeowner, rent. Home ownership thereby encompasses two roles: renter and landlord.

\footnotetext{
${ }^{5}$ For the present purposes, Asian and Native American households are included with whites due to their relatively small representation in the population.

6 The market for reverse mortgages has been small but appears to be growing; to date fewer than 40,000 reverse mortgages have been underwritten. This total is expected to grow due to the Federal Housing Administration's adoption of the Home Equity Conversion Mortgage (HECM) program under whose auspices about half of reverse mortgages have been underwritten. The introduction of government and secondary market mechanisms as well as educating the elderly to the availability of these products should spur growth; see for instance the Fannie Mae's November 1996 Home Keeper Mortgage program which is similar to HECM but provides higher loan limits (Cocheo 1996, Nixon 1996). Rasmussen, Megbolugbe, and Morgan (1995) examine data from the 1990 census to assess potential market demand. Limiting potential users of such products to households with heads older than 69 with fully paid mortgages and home equity in excess of $\$ 30,000$, they find a potential 1990 market of as much as 6.7 million homes.
} 
As long as there is debt owed on the house, mortgage payments reflect two components: consumption in the amount equivalent to the rental value of the property, and savings in the amount that an additional mortgage payment represents increased equity in the house. Households that have paid off their mortgages are no longer increasing housing equity, but more importantly, are not paying for their consumption of housing services. Since shelter is one of the largest consumption expense of most households, paying off the mortgage represents a substantial decrease in income to meet consumption needs for those with wholly-owned housing. We believe that this argument supports the case for including most of housing wealth when assessing the sufficiency of assets for retirement.

\section{Changes in Wealth Levels Over Time for a Given Age Group}

The HRS data presented above gives a detailed snapshot of a specific cohort at one point in time. Ideally we would prefer a time series of wealth data for the same households, from which we could assess saving behavior and changes in wealth accumulation. In the future this should be possible, but thus far we cannot make direct comparisons with the past as there exist no comparable data either for the identical individuals in the past, or for a similarly-aged cohort at a distant enough time point in the past.

One way of exploring changes in cohort wealth over time is the approach taken by the Congressional Budget Office (CBO, 1993). This study used data from the Survey of Consumer Finance (SCF) from 1962 and 1989 to compare wealth of two similarly aged cohorts at two different points in time: baby boomers born between 1946 and 1964, and their parents. Baby boomers were then divided into two groups, the first-wave boomers (age 35-44 in 1989), and a second wave born in the second half of the baby boom (age 25 - 34 in 1989). Those classified as "first wave parents" were 1962 survey participants age 35-44, and "second wave parents" were those age 25-34 in 1962. (Households were not intentionally re-sampled in the SCF, so the "parent" group are not the actual parents of the particular baby boomers in the later survey.)

Median financial wealth figures for baby boomers as well as the parents' generations are summarized in Table I.A.4 by income quintile.? In the lowest income quintile, baby boomers in 1989 had less wealth than their parents in 1962 . The first wave boomers had one-third less wealth, and the second wave had about half as much accumulated wealth, as their parents at the same age. In both cases however, the amounts of wealth accumulated are very low. This pattern generally reverses as we proceed up through the income quintiles. The median younger boomer household has nearly half again as much accumulated wealth as the median young parent household at the same age, $\$ 9,900$ versus $\$ 6,700$. For the quintile with the highest incomes, younger boomers saved almost three times as much as their parents at the same point in their lives, $\$ 80,800$ versus 
$\$ 28,000$. The conclusions are much the same for the older boomer group, relative to its parents. The median older boomer household saved nearly $85 \%$ more than its parents, $\$ 59,500$ versus $\$ 32,200$. Once again the increase in saving is most dramatic among the highest income quintile which holds more than twice the wealth of their parents, $\$ 184,000$ and $\$ 89,000$, respectively.

One explanation for the wealth increases experienced by baby boomers relative to their parents is that educational attainment rose substantially across cohorts. The fraction completing high school rose from three-fifths to four-fifths, and those with four-year college degrees went from $10 \%$ of their cohort to nearly one quarter of the later cohort. Those completing college saw median wealth gains on the order of $50 \%$, while those without high school diplomas saw a drop of some $56 \%$. Another explanation may be attributable to the relative performance of bond, equity, and real estate markets in the 1980's as compared to the 1950 's. The 1980 's was predominately a period of strong growth for all three asset classes, and returns on the same assets during the 1950's were not as robust. Whereas these returns benefited the boomers' parents just prior to retirement, the pattern increased wealth for the baby boomers earlier in life, improving their relative position when age is held constant.

\section{The Role of Assumptions in Determining Wealth Values}

Survey respondents in the HRS and in other studies probably give as reasonable answers as can be expected regarding their net financial wealth and housing wealth.8 By contrast, survey respondents would have a much harder time computing wealth values for contingent sources such as social security and pensions. Rather than asking people to give wealth values for these, analysts usually ask respondents their anticipated benefit levels (per month or per year), and then convert these into expected present value amounts. Of course, the wealth figures thus computed are sensitive to the underlying assumptions employed in deriving the present value of these flows.

In particular, pension and social security accrual amounts and wealth values are influenced by assumptions regarding expected future nominal interest rates, inflation rates, and rates of real wage growth. Raising (lowering) the nominal interest rate decreases (lowers) the wealth value of future pension and social security benefits. Under current law, social security benefits are indexed for inflation but private pensions are not, so that raising (decreasing) the assumed inflation rate decreases (increases) the wealth value of pensions but does not change real social security values. Raising or lowering the assumed real wage growth correspondingly raises or lowers the wealth values of social security and pension plans.

\footnotetext{
${ }^{7}$ All figures are expressed in 1992 dollars using the Consumer Price Index (CPI) to allow for comparability with the HRS figures.

8 For a discussion of the advantages of the HRS approach in eliciting income values see Gustman and Juster (1996).
} 
In the data derived from the HRS and presented thus far, the approach has been to use the "intermediate" assumptions adopted by the Social Security Administration for purposes of forecasting future paths of the Social Security Trust Funds through the 75-year projection period required by Congress. Of course other assumptions could be used in the wealth computations, but for purposes of comparability, authors such as GMSS (1997) and Mitchell, Olson, Steinmeier (1996) have tended to rely on these for at least first-round benchmarks.

It is also the case that converting retirement benefit flows into wealth values depends on assumed mortality rates; GMSS and Mitchell et al. use projected rates based on data supplied by the Office of the Actuary at the Social Security Administration. These figures could also be examined to explore their sensitivity; for instance Lee and Skinner (1996) compare demographers' forecasts with those used by the Social Security Administration and conclude that life expectancy is probably increasing more quickly than the SSA estimates.

The importance of other assumptions in computing wealth values should also be highlighted. For instance, many wealth computations assume that the worker retires at the normal retirement age, say age 65 , but in reality many people retire before that point. This could upwardly bias measured social security and pension wealth.9 Working in the opposite direction is the fact that social security wealth values assume that benefit formulas currently in effect will still be in effect at the households retirement date. However the social security system faces potential insolvency, and it is likely future reforms will substantially alter both the level and the form of future benefits. ${ }^{10}$ In support of the figures given thus far, however, we believe that the HRS data described above are reasonable for the generation currently on the verge of retirement. It might be possible to capture the greater uncertainty regarding benefits facing younger generations by using a higher interest rate to discount the benefit flows,

The bottom line is that different assumptions will change social security and pension wealth figures somewhat. On the other hand, irrespective of assumptions, these two programs would still represent the bulk of retirement wealth for the vast majority of US households. Therefore while we encourage the further use of alternative assumptions to check sensitivity analysis, it is important to go on to the next step - determining whether these levels are sufficient for retirement.

\section{B. Benchmarks - How do we know How Much is Enough?}

In order to determine whether these wealth values are adequate, it is necessary to establish benchmarks against which household saving can be compared.

${ }^{9}$ GMSS calculate most of their pension wealth data by projecting service to retirement and then prorating by service to date. An alternative (that this study also explored) calculates benefits based on service and salary to date; this would correspond to the current liability of the employer and produce lower pension wealth values.

${ }^{10}$ For a discussion of options see the Final Report of the Technical Panel on Trends in Income and Retirement Saving (TIRS 1996) available also on the internet at www.ssa.gov). 


\section{The Life Cycle Model -A Theoretical Basis for Evaluation}

The traditional economic approach to examining retirement wealth builds on the life cycle model originally proposed by Modigliani (Modigliani and Brumberg 1954; Ando and Modigliani 1963) and others. The idea is a simple one, depicted in Figure I.B. 1. Here age is graphed against dollars, and three profiles are shown. The first line represents earned income: labor earnings are assumed to grow until retirement age, after which earnings fall substantially. The second line represents the households consumption stream: if there were no uncertainty about earnings, mortality, or taxes, the consumption line would be flat. Consumption exceeds earned income during the early part of the worklife, so that the household must in effect borrow against future income to finance current consumption. (This would include paying for child rearing expenses, college tuition, or downpayments on a house). Later in life, the lines cross and consumption becomes less than earned income; at this point the household pays off past debts and then saves for retirement. Finally, still later, the lines cross yet again: at retirement, the household now consumes out of savings to offset cuts in earned income.

In the baseline case with a zero rate of interest, the area under the earned income curve is exactly equal to the area beneath the consumption curve. More generally, when interest rates are positive, the area beneath the consumption line exceeds that under the earned income curve, reflecting returns on accumulated wealth.

Many extensions of this life cycle theory have been suggested, with the most important and interesting ones exploring how uncertainty affects consumption and saving profiles with age (e.g. Hubbard, Skinner, and Zeldes 1994; Deaton 1992, and others). Many sources of uncertainty are germane, including the fact that people do not know when they will die, they experience fluctuations in income as they age, they face changes in their health, and they are subject to fluctuations in asset values and returns.

The third line in Figure I.B. 1 represents the case of consumption when a particular type of uncertainty enters the picture; here the household does not know life expectancy with certainty. The effect of this uncertainty is to make the consumption line become humped, rising during the working years and declining during the retirement years. (In any event it still changes less drastically with age than does earned income.) This new shape is the result of the household weighing needed saving to finance future consumption by the probability of living, and comparing that to the value of wasted consumption due to saving if the household does not survive.

\section{Adequacy Benchmarks}

While the life cycle model is useful in theory, implementing it in practice proves to be complex. Many in the financial advisory community suggest computing a number known as the "replacement rate", or the ratio of household income needed to finance desired retirement consumption divided by annual pre-retirement income. The number is a spiritual descendent of life 
cycle theory, but implicitly assumes that post-retirement consumption should be equated to some fraction of the sum of pre-retirement consumption plus retirement saving. More sophisticated computations adjust retirement consumption to exclude work related and education expenses (e.g.: clothing, travel, and related entertainment expenses), and to account for the differential taxation of workers and retirees.

Empirical efforts to compute retirees' target replacement rates yield a wide range of estimates depending on what is included in the computations and which dataset is used (McGill et al. 1996). For example, early studies recommended replacement rates declining in income: a household with $\$ 10,000$ in annual income would be encouraged to have a replacement rate of $80 \%$ (for an annual retirement income of $\$ 8000$ ), while the household earning $\$ 50,000$ before retirement was encouraged to have a replacement rate of about 55\%. More recent work by Palmer (1988, 1991, 1993) updated prior studies to reflect changes in tax law and concludes that gross replacement rates have varied over time; his results appear in Figure I.B.2. Palmer 's results are problematic in that he argues that replacement rates decline as a function of income in 1991, but rise with income in 1988 and 1993 for higher income households. Also his results indicate substantial volatility in recommended replacement rates, a conclusion that makes retirement planning with the replacement rate datum quite difficult.

A different approach is proposed by Bernheim $(1992,1993,1994)$, who works with an explicit variant of the life cycle model. He models the household as making choices over its lifetime, facing not only uncertainty over mortality but also shocks to earned income, interest rates, inflation rates, and even tax rates. His approach assumes that a household seeks to maximize the present value of its expected utility from future consumption given earnings, net government transfers (i.e.: social security taxes and benefits), and accumulated wealth in each period. Consumption per period is the decision variable by which the household optimizes. Since saving is simply income less consumption, optimal consumption in a period determines saving endogenously.

In this framework, a households saving rate is then determined through dynamic programming (DP), using a process of backward induction illustrated in Figure I.B.3. ${ }^{11}$ Unlike the

11 In the Bernheim approach, the problem is solved for the last possible period, $t=T$. Because there is no further period, at that point the household consumes all its wealth and income. The same problem is then resolved for period $t=T-l$ allowing for expectations of the final period. In other words, the household maximizes utility in period T-l in a way that captures the uncertainty of living to period $\mathrm{T}$. If it were known with certainty that the household survives to the last period savings would be high, if it were known with certainty that the household would not reach the last period all assets would be consumed at T-l. Actual savings then weights these two possibilities and arrives at an intermediate solution which finds a value of $\mathrm{C}_{\mathrm{T}-1}$ to maximize the problem $\max U\left(\mathrm{C}_{\mathrm{T}-1}\right)+\mathrm{p}$ T-1 $\beta \mathrm{U}\left(\mathrm{C}^{*} \mathrm{~T}-1\right)$ where $U(C)$ is the utility of consumption, $\beta$ is the rate of pure time preference (discount) and pr.1 is the probability of surviving from time T- 1 to time T. Once the optimal saving rate is determined for period $\mathrm{t}=\mathrm{T}-\mathrm{l}$, the process can be solved for period $\mathrm{t}=\mathrm{T}-2$, and in a similar manner for periods back 
standard replacement rate methodology described previously, the DP approach does not generate saving rates that are a constant percentage of income; rather, the optimal saving rate path is now increasing in age up to retirement. Intuitively, this is because as the household ages, its likelihood of surviving to retirement increases. (An increasing saving rate can be built into the replacement rate methodology, but the shape of this increase must be determined explicitly whereas for the DP problem it is a result of the solution methodology and the parameterization of the model.)

Having computed optimal saving rates from the DP model, Bernheim then goes on to evaluate actual saving patterns reported in a Merrill Lynch survey on household income and wealth. The results are expressed as an index of savings adequacy; thus a value of $100 \%$ would indicates that workers are saving at exactly the appropriate target pace for retirement under the Bernheim parameterization of the life cycle model. To sum up the findings, the author reports that asset accumulation indices fall between 16\% (pessimistic assumptions) and 55\% (optimistic assumptions), with his mid-range estimate set at $35 \%$. This scenario anticipates no change in government benefits and fiscal policy. ${ }^{12}$ The author concludes:

[E]ven relatively young households ( 35 to 45 years old) generally need to save 9 to $19 \%$ of their after-tax income, and individuals not covered by private pension plans should be even more frugal. On average, a household in the 35 to 45 age bracket that does not expect to be covered by a private pension should save between $13 \%$ and 25\% of after-tax income, and this figure should rise with age. (Bernheim 1993: 1)

It is important to note that Bernheim omits housing wealth in calculating his basic statistics. This is reasonable, he argues, since retirees generally die in the homes in which they retire, and surveys indicate that people do not desire to sell housing assets to generate retirement income. However, in a data appendix the author demonstrates that including housing equity raises the average adequacy level substantially -to $84 \%$. While this figure is much higher, it still represents a shortfall.

\section{The Importance of Assumptions}

It should be evident to the reader that the role of assumptions is critical in determining whether people have saved 'enough for retirement. Both the replacement rate (RR) and dynamic programming (DP) methods just described are powerfully influenced by assumptions regarding mortality, interest and inflation rates, and retirement ages. Another key issue in the RR method is how to value a single premium annuity that could be purchased with retirement wealth. Ideally, a household could purchase such an annuity at an actuarially fair rate and use this annuity flow to

to the starting point. The problem is solved for a number of simulated economies reflecting random draws in the uncertain variables to give a distribution of optimal saving rates.

12 Results are also supplied assuming that social security is made solvent. Under the most pessimistic scenario examined in that study, complete elimination of social security benefits, the midpoint value of saving adequacy is only $9.3 \%$. 
live on in retirement. However, due to sales loads, insurer profits, and adverse selection, this may be a tenuous assumption and it is discussed in greater detail below.

In using the DP model, still other assumptions take on salience, namely the set of assumed parameters used to characterize household utility functions. In particular the DP model emphasizes behavior under uncertainty, so a crucial assumption pertains to the choice of the households risk aversion parameter. This parameter embodies an assumption about how sensitive a household will be to fluctuations in its consumption path or permanent income. In general, the larger the absolute magnitude of the risk aversion parameter, the more sensitive the household will be to variability and shocks to consumption. More risk averse households will tend to save more in a precautionary manner, to protect against consumption shortfalls in relatively rare but unpleasant states of the world.

Another critical parameter in the DP model is the assumed rate of return on accumulated assets, which reflects the relative price of consuming today versus in the future. A higher rate of return has two effects: it makes current consumption more expensive (since the consumer gives up more interest), but it makes current saving more valuable by giving the saver more "bang for his buck". For example, $\$ 1$ saved for a year at $8 \%$ buys $\$ 1.08$ worth of consumption next year (assume all figures are real); at $10 \%$ interest, the corresponding figure is $\$ 1.10$. But $\$ 0.58$ saved for 30 years at $10 \%$ buys what $\$ 1$ saved at $8 \%$. On the other hand, each cent saved does buy that much more in the future and that may make saving that much more attractive. In general, which effect dominates in the DP framework is largely determined by the risk aversion parameter.13

Focusing for a moment on the particular choices Bernheim makes to parameterize important behavioral parameters, it must be concluded that his choices are on the conservative side - in other words, the assumptions made are consistent with a finding of too little rather than too much saving. The risk aversion parameter he uses is set to -3 , a value at the risk-averse end of what has been used in the literature. 14 Interest rate values used are drawn from a historical series of 3 month Treasuries; this too is a conservative assumption, inasmuch as returns on longer

13 This ambiguity does not exist in the RR model. In the RR model the amount of terminal assets needed are fixed and higher rates unambiguously lower the necessary saving rate.

${ }^{14}$ Bernheim uses a utility function in each period is of the form

$$
\frac{(c-m)^{y}}{\mathrm{Y}}
$$

where $\mathrm{m}$ is a floor level of consumption (set at $\$ 10,000$ in 1993 dollars) and $y-1$ is the elasticity of marginal utility, or similarly, the negative of the coefficient of relative risk aversion $R$. This parameter indicates the saver's sensitivity to consumption fluctuations, with greater values of $R$ indicating greater desire to smooth consumption patterns through time. Bernheim uses a value of -3 for $\gamma$, or $R=4$. This is at the high end of values commonly seen in simulation models. The most commonly observed range is $0 \leq \mathrm{R} \leq 2$, where 0 is linear utility (risk-neutral) and 1 corresponds to logarithmic utility. 
maturity Treasuries have historically exceeded those for the short-term instruments. ${ }^{15}$ This ignores the still higher returns available on stocks, but as holding stocks means bearing commensurately more risk, this may not be palatable to a risk-averse investor.

As a result, these two behavioral parameters generate relatively high target savings levels. Another issue is the fact that Bernheim assumes workers in his DP model retire at the age of 65, so that they need income for fewer years than reality (actual retirement ages are around 62 in the US). This would moderate the effects of the previous assumptions. Whether alternative parameterizations of these key assumptions would yield substantially different results is not indicated in this study. Bernheim's figures are also generated only for respondents to the Merrill Lynch survey, a sample that has subsequently been found to be somewhat wealthier than the population as a whole.

\section{Wealth Accumulation on the Verge of Retirement}

In this section we use HRS data to determine whether accumulated wealth is adequate for retirement in a nationally representative sample of the older population. The results appear in Table I.B. 1. As prescribed by the replacement rate methodology, we begin with an example household with characteristics similar to HRS medians. Our household is a married couple with both husband and wife age 56 in 1992 (the median age for HRS respondents). Total annual household income is taken to be $\$ 46,000$, consistent with median values reported by GMSS (1997) and the present authors. Social Security wealth is taken from Mitchell, Olson, and Steinmeier (1996).

The approach we take is to roll forward this median households current total wealth to age 65. A detailed description of how wealth is rolled forward and other procedures can be found in Moore and Mitchell (1997). In brief what we do is as follows:

i) Net financial wealth is rolled forward assuming assets are held in a portfolio of $60 \%$ bonds and $40 \%$ stocks, with these assets earning returns consistent with their average real historical returns over the period 1926.1995 .

ii) Net home value computations assume wealth is held in a single owner-occupied house and housing wealth increases with the increased amortization of the mortgage's principal. In other words, zero real appreciation of housing stock is assumed.

iii) Pension wealth is assumed to increase on the presumption that the households pension allocation consists of one-third defined contribution and two-thirds defined benefit; these are assumed to grow in line with the rates in GMSS.

15 For example, the spread between the yields on 3 month and 30 year Treasuries was approximately 150 basis points in February 1997 (CNN Financial Network 2/21/97). 
iv) Social security wealth increases are based on the differences between current value and the projected value for a married couple as calculated in Mitchell, Olson, and Steinmeier (1996) using actual earnings profiles.

The projected value of current assets at age 65 is $\$ 445,300$. (See Table I.B. 1.)

Given the projection of household wealth at age 65, the next step is to determine household needs in retirement. Here we express need as the wealth level required to generate income consistent with a specified pre-retirement income replacement rate. On the presumption that real income (of $\$ 46,000$ in 1992 dollars) is constant to age 65 , we seek to determine how to finance consumption at any given fraction of $\$ 46,000$ per year in retirement. Results are presented under replacement rate assumptions of both $70 \%$ and $80 \%$. Based on prior studies, as summarized in Figure I.B.2, these are reasonable bounds on the suggested replacement rates for a household of this income level.

For each of the two replacement rates, values are calculated under three alternative real discount rate scenarios and two annuity assumptions. The baseline real discount rate scenario is $2.5 \%$, corresponding to the 70-year average of real returns on long-term government bonds. This is bounded by a conservative assumption of $1 \%$ and a more aggressive assumption of $4 \%$ (real). Needed wealth values are calculated under two annuity assumptions - $100 \%$ joint and survivor annuity, that presumes the surviving spouse needs the same income after a partner's death as when both partners were alive, and a 50\% joint and survivor annuity, that assumes income needs are halved when one spouse dies. Actual need likely lies somewhere between these two values, inasmuch as some expenditures such as housing probably do not decrease, while others such as food, travel expenditures, and clothing would decline.

Having computed the amount needed to sustain consumption, we subtract the projected value of the median households current assets. The shortfall reflects the additional wealth required to meet retirement need. Consequently we compute how much the household would need to amortize this shortfall by its retirement date, calculated assuming level savings and returns commensurate with a portfolio of $40 \%$ stocks and $60 \%$ bonds.

It will be noted from Table I.B.2. that the resulting saving rates span a wide range under the baseline interest rate assumption -from a high of $39 \%$ of annual income (i.e. $\$ 17,800$ per year), to a low of $1 \%$ of income (i.e. $\$ 500$ annually). In our judgment the mid-range value of $23 \%$ of income) is probably more in keeping with what the median household might consider; this assumes a $70 \%$ replacement rate with a $100 \%$ survivor benefit. A lower $14 \%$ saving rate is achievable with an $80 \%$ replacement with $50 \%$ survivor benefit, and probably represents a lower bound on required household saving.

As we move from the baseline interest rate assumption the range of prescriptions becomes even wider. With a very conservative interest rate and annuity assumption, the methodology 
would mandate that the median household would have to save nearly two-thirds (63\%) of annual income until retirement, a target not sustainable by most. Under the more aggressive assumptions the median household need save nothing beyond its current assets. This range illustrates how sensitive saving advice is to underlying assumptions, even given a relatively short planning horizon.

It is interesting to compare our results to the saving prescriptions offered by Bernheim (1994) using the DP methodology. Bernheim's approach advises an after-tax saving rate of 19\% for a 55 year-old married couple having traditional pensions and an annual household income of $\$ 50,000$. Surprisingly, his number is at the low end of our estimated range as required rates from pre-tax income would be lower than those from after-tax income. However the discrepancy can be reconciled by noting that the "on-track" hypothetical couple in Bernheim's world holds approximately $\$ 90,000$ of retirement wealth. Using our own HRS sample, we find that the median couple holds one-third less financial wealth in reality - only $\$ 59,300$ - so the median HRS household would need to undertake additional saving using both approaches.

While these figures do suggest assets are inadequate to cover pre-retirement consumption levels, it might be asked whether using other criteria would produce better results. Table I.B.3. compares annuitized consumption flows with poverty line level spending, and a somewhat mixed picture emerges. Less than $5 \%$ of the respondents overall were at risk of falling into poverty in retirement. This risk is concentrated among blacks and single-person households who were far more likely to have inadequate income levels to bring them over the poverty line.

\section{Conclusion}

In this section we have shows that there is a great deal of evidence regarding the adequacy of retirement saving. However analysts have suggested a wide range of different benchmarks, and there is no single and simple "right" benchmark applicable to all people in every circumstance. At first glance, the evidence from the HRS would seem to indicate that on average those near retirement are in a relatively comfortable position, once social security benefits and pensions are included. Nevertheless, when we project these assets to retirement age and compare them to an income-related benchmark, even the median household faces a large saving task ahead. Whether this is feasible will be taken up in the next section.

It is also important to remember that our calculations for the median older household mask a great deal of diversity in the older population taken as a whole. In today's world, older households that are white, have higher income, are highly educated, and are married generally appear relatively better prepared for retirement. In contrast, poorly educated, low income, nonwhite households may be in far worse shape.

What the future will hold for the baby boomers - people today 10 or more years from retirement - is somewhat less clear. If this cohort continues saving at rates faster than their 
parents did, they may be in good shape. On the other hand, there is no guarantee that today's workers will benefit from the windfall runup in assets that recent history bestowed on their parents. The baby boom also confronts greater uncertainty in social security and pension benefits; and the shift from defined benefit to defined contribution pension plans will probably push more responsibility for their own welfare onto baby boom households. All in all, it seems clear that the baby boom cohort is not experiencing a dramatic saving shortfall that some doom mongers have portended. On the other hand they would be prudent to save more than they are, and relatively modest changes in saving patterns today may avert the need for drastic changes tomorrow.

\section{Incentives and Disincentives for Saving}

If we take as given that households tend to save too little for retirement, the next question is why and what might be done to rectify the situation.

\section{Why Might Households be Saving too Little?}

One potential explanation for why households save too little is that some people simply might not be able to afford to save. This might be true, for instance, if income barely covers a subsistence level of consumption. However this view is not likely to hold for other than the poorest of the poor in the US.

A second possible explanation for undersaving focuses on the inherent difficulty solving of the households planning problem. As can be seen from the discussion of the DP model above, many issues must be considered and assumptions made about inherently uncertain future variables including future income streams, interest rates to be earned on various asset classes, tax rates and issues, future inflation rates, and mortality. Also, as demonstrated earlier, calculated saving rates are quite sensitive to changes in assumptions, and experts may not agree on what these assumptions should be.

Few experts have actually tried to evaluate whether people seem able to forecast the future particularly accurately. Of note are Bernheim's (1996) study assessing financial literacy and Hurd and McGarry's (1995) analysis of subjective mortality assessments. Bernheim finds households generally lacking in financial knowledge, and he ties this financial illiteracy to under-preparation for retirement. Inasmuch as saving rates are an increasing function of financial and economic literacy, he concludes that such ignorance may be depressing saving rates. The work by Hurd and McGarry finds that people can predict fairly accurately the likelihood of surviving to age 75 , but they tend to overestimate the probability of living to 85 . This suggests that people should tend to oversave rather than undersave, so the evidence is not supportive of the undersaving hypothesis.

Another rationale for too little saving may be lack of self control (Thaler 1994; Sheffrin and Thaler 1988). This theory contends that people face a conflict between a desire for immediate gratification versus a forward-looking need to save for the future. The psychological perspective asserts that people develop so-called "mental accounts", and treat money differently depending on 
which account it is attached to. Thus some income surprises tend to be consumed immediately, while others tend to be saved for future consumption. Thaler argues that to increase saving, people need to have funds deposited automatically through payroll deductions or mandatory saving of tax refunds.

Another potential explanation for undersaving patterns relies more on incentives rather than psychological constructs. This approach emphasizes the role of government in providing an income safety net, which various authors have argued discourages precautionary saving (Gokhale, Kotlikoff, and Sabelhaus 1996; Hubbard, Skinner, and Zeldes 1994, 1995). Specifically, a wide range of government programs for the elderly is seen to have provided them with longevity insurance. No longer worried about living beyond their income (in the case of social security), or paying catastrophic medical costs (in the case of Medicare and Medicaid), the elderly rationally can view such government programs as curtailing the need for households to save. This is particularly relevant given asset tests for programs such as Medicaid nursing home support, where older persons must first exhaust their own funds before seeking government assistance.16 The logical extension of this behavior is that households expecting to use these services will increasingly tend not to save at all; those who are wealthy must save more since for them, since the possibility of government assistance is remote. This pattern will then exacerbate the resulting inequality in accumulated wealth.

In sum, analysts have offered many different explanations for low saving rates. The relative importance of each of these reasons - lack of substantial income, poor understanding of financial and related issues, psychological issues, or the unintended influences of government programs - is unclear. Most of these reasons have sound basis in economic theory but have been relatively untested empirically. As good data become available it will be possible to investigate these hypotheses.

\section{Do Tax Inducements for Saving Work?}

An important feature of most dedicated retirement saving programs is the advantaged tax status they provide for saving. Income saved through these programs reduces taxable income in the year saved. In addition, capital gains, dividends, and interest payments, are not taxed as they accumulate. Taxes are paid when the assets are withdrawn. By the time they are withdrawn, the saver is generally in retirement and hence in a lower tax bracket. The tax deferral mechanism therefore effectively raises the after-tax rate of return on these assets.

\footnotetext{
${ }^{16}$ In some cases this has led to some elderly transferring assets to their children or other relatives to meet asset tests and to avoid spending their own money on long term care when they can take advantage of the government 's largesse. In response to these actions states have recently initiated tests governing asset transfers to minimize gaming of the system. Eligibility is now a function not only of the elderly individual's current assets but also past assets over a three year period.
} 
This observation raises two important research questions for researchers concerned with saving behavior and public policy. The first is whether this tax inducement raises saving rates. The incentives are certainly intended to induce households to save more, but some believe that all that happens is that saving is just shifted from taxed to tax-deferred vehicles. The second question is whether the increase in saving generated by these tax incentives justifies the foregone tax revenue that it costs.

The literature on this subject is long and the arguments contentious. Early work by Feldstein (1977), Diamond and Hausman (1980), and Munnell (1982), examined how defined benefit pension plans influenced saving. These studies assumed that participants in defined benefit plans see the promised deferred benefit is effectively an exchange for reduced wages. Employees are saving indirectly through the employer-provided plan. Empirical estimates of this tradeoff suggested that private, nonpension, saving fell by between 32 and 42 cents per dollar saved through a defined benefit plan. This is analogous to looking at the proverbial glass as half empty. A more positive view is defined benefit plans raise aggregate saving. Every dollar saved through a taxprotected dedicated retirement vehicle would be predicted to raise aggregate saving by 58 to 68 cents.

Subsequent studies have been numerous, many of them examining how changes in the tax code affected defined benefit pension values especially for employees with high salaries, and also how tax law changes affected employers' ability to prefund for promised benefits. While discussion of these specific changes are beyond the scope of this paper (the interested reader is referred to McGill et al. 1996), these changes have been important to providers of defined benefit pension plans, and may explain why so few employers are offering the DB plan type when designing new plans.

A very active line of recent research has focused on the saving effects of define contribution pensions, in particular Individual Retirement Accounts (IRA 's) and 401(k) plans. IRA 's were first allowed in 1974, to provide a tax-preferred saving mechanism for those individuals with no company-sponsored pension plan. Rules governing these plans were then loosened by the Economic Recovery Tax Act of 1981, expanding IRA eligibility to most American households and raising contribution limits. Shortly thereafter the rules were again tightened. In 1986, the Tax Reform Act limited higher-income households' tax deductible contributions to these plans. Coincident with these changes, and probably largely because of them, IRA contributions see-sawed from $\$ 5$ billion in 1981, rising to $\$ 38$ billion in 1986, and then fell to less than $\$ 8$ billion in 1994 (Hubbard and Skinner 1996).

Over the same time period 401(k) plans saw tremendous growth. The tax advantages of 401(k) s mirror those of IRA 's, but there are important differences. The most important of these are that $401(\mathrm{k}) \mathrm{s}$ are employer sponsored and are tied to employment, and employers can match 
employee contributions in a tax protected way, subject to certain rules and regulations. According to Poterba, Venti, and Wise (1996c), contributions to 401(k) grew from almost zero in 1981 to more than $\$ 63$ billion in 1992. Figure I.C. 1. illustrates the relative growth of 401(k) plans versus all other employer-provided plans over the period 1984 to 1992. Contributions to 401(k)'s soared from $18 \%$ to $50 \%$ of all pension contributions. This enabled total pension assets attributable to $401(\mathrm{k})$ 's to rise from less than $9 \%$ to more than $26 \%$. In this period, participants covered by $401(\mathrm{k})$ 's rose from about $12 \%$ to nearly $35 \%$ of employees with sponsored pension plans.

The question of central importance for our purposes is whether these IRA and 401(k) contributions represent new saving, and if so, how much? One group of researchers contends that these contributions represent considerable new savings (Poterba, Venti, and Wise 1993, 1996a, 1996b, 1996c). In a series of studies this team concludes that between 45 and 66 cents per dollar contributed to an IRA represents new saving, deposited at the expense of current consumption. The balance, between 34 and 55 cents, comes from the tax subsidy and reallocation of existing saving. The evidence is more equivocal for $401(\mathrm{k})$ contributions, mainly because of the difficulty researchers have had in obtaining good data indicating how employer match provisions work in available datafiles. Also, some 401(k) plans replace terminated defined benefit plans and represent a transfer from one saving mechanism to another, rather than new saving. In all, though, when Poterba et al. compare the saving behavior of households with $401(\mathrm{k})$ plans to those without, they conclude that both types of households have non-pension saving that is quite similar. From this and other evidence, they deduce that the bulk of 401(k) saving is new saving.

Opposing this group is another research team arguing that most IRA and 401(k) contributions are financed through tax savings and shifting of saving from taxed vehicles to tax. favored vehicles, and not from reductions in current consumption (Gale and Scholz 1994; Engen, Gale, and Scholz 1996). Considering a scenario where the IRA contribution limit is raised by $\$ 1000$ (from $\$ 2000$ to $\$ 3000$ ), Gale and Scholz conclude that only two cents per dollar of additional contributions would represent new saving. This assumes all of the households tax reduction is saved; were some of the tax saving used for current consumption, then they would argue that IRA 's stimulate no new saving (and might even reduce it). Their findings for 401(k) plans are of a similar nature.

Who is right? In a pair of excellent recent critiques, Bernheim (1996) and Hubbard and Skinner (1996) review the methodology, highlight data difficulties common to both studies, point out problems unique to each of the authors 'studies, and draw out key sensitivities to specific assumptions and estimation techniques. Both reviews come to the same conclusion: the optimistic studies likely overstate net additions to saving derived from tax incentives, and the pessimistic studies likely sell the programs short. A mid-range figure 26 cents per dollar of contributions is 
suggested as a conservative but reasonable estimate of the new saving generated by new IRA contributions (Hubbard and Skinner 1996).

Whether an increase in saving of this magnitude justifies the cost in foregone taxes is a complex matter. To evaluate it, Hubbard and Skinner calculate the ratio of the change in private capital accumulation per dollar of IRA contributions to the change in net tax revenue per dollar of IRA contribution. This ratio indicates the amount of saving generated per dollar of tax subsidy and is calculated under three scenarios. Under the first and baseline scenario using the 26 cents figure and tax laws in place in the mid-1980's, each dollar of tax subsidy generates $\$ 2.21$ in increased saving. The second scenario allows for secondary effects that the supply of IRA funds to corporations indirectly generate in income and corporate taxes. Under these revised assumptions, each dollar of tax subsidy generates $\$ 4.84$ in increased saving. The third scenario recalculates the figure using current tax laws and obtains a result of $\$ 2.09$ in new saving for dollar lost in tax revenue.

Despite the range of opinion regarding the saving stimuli associated with these programs the general tone of the results is encouraging. That is, if IRA contribution limits were to be raised, it indicates that there would be a surge of new saving through IRA's. The variance in opinion, however, underscores the need for additional research in this arena and application of statistical methods to new and varied data sets.

\section{Pension Plan Design and Participant Education}

Those covered by a company-sponsored 401(k) plan face encouragement to save via the contribution match made by the sponsoring employer. Matches are restricted by law but vary widely in practice. For example, employers are not obligated to offer a match, but might match half of employee contributions up to a specified contribution limit. Total employee contributions are limited to the lesser of $15 \%$ of compensation or the government contribution limits, unless the sponsor sets a lower limit. Caps on matches are generally determined so that the plan does not violate discrimination rules requiring that highly paid employees do not enjoy disproportionate gains from the plan relative to more modestly paid individuals.

Most analyses of household saving behavior undertaken by economists use large cross section data sets such as the Survey of Consumer Finance (SCF) or the Current Population Survey (CPS). In analyzing 401(k) contribution behavior these surveys have the common problem that they lack key information on the specifics of employer-sponsored plans. Therefore users of these data sets to explore 401(k) saving behavior have to make assumptions about employer matches, for instance using average match values from some other source. Imputation of match values in this way can mask the importance of these matches and may lead to biased or even incorrect results. A different but equally critical problem is these data sets do not follow the same households over a 
number of time periods. This makes it impossible to examine changes in 401(k) saving behavior among the same households over time.

To address the role of employer match rates, analysts have turned to 401(k) plan administrators seeking more detailed data from employee records. One such study examined contribution behavior in a 401(k) plan sponsored by a medium-sized manufacturing firm over the five years between 1987 and 1991 (Kusko, Poterba, and Wilcox 1994). During this time, the employer match rate changed annually, but employees demonstrated practically no sensitivity to these changes in match rates. In fact, it appeared that employees effectively went on "auto-pilot". Three-fourths of those eligible to participate either did not contribute, contributed up to the point where the employer would no longer match contributions, or contributed to the maximum degree the plan would allow. Once a contribution rate was set, it did not change.

Studies such as this one are informative as case study explorations of individual plans, but their results cannot be extrapolated to draw a bigger pictures of the 401(k) world. Is the behavior of the firm examined unique, or is it representative of common behavior? For example, while they may paint an accurate picture of behavior in medium-sized manufacturers, what could we infer for a large bank with a more heterogeneous employee mix? A richer data set with information on 19 firms ranging in size from 700 to 10,000 employees is explored by Clark and Scheiber (1996). Although the data are drawn from a single year, inferences on sensitivity to match rates can be drawn from the variety offered across plans assuming individuals behave similarly. The authors observe that participation rates are an increasing function of match rates:

[R]elative to being in a plan with a 25 percent match rate, a worker covered by a plan with a 50 to 75 percent match rate is 28 percentage points more likely to participate in the $401(\mathrm{k})$ plan. Workers in plans with a 100 percent match rate are 47 percentage points more likely to make an annual contribution to the plan than those in a plan with only a 25 percent match rate. (Clark and Scheiber 1996: 15)

Higher match rates also stimulate greater contributions among those who do contribute; specifically pension contribution rates for those with $100 \%$ matches are two percent of salary higher than for those receiving a 25\% match. Using a database from the 1993-94 KPMG Peat Marwick Retirement Benefits Survey, Bayer et al. (1996) also conclude that plans with matches have higher participation rates -by 15 to 17 percentage points - than do plans without matches.

A different but related issue is how pension plan participants respond to employer efforts to educate them about retirement saving and their particular plans. Clark and Schieber find that providing specifically tailored communication about a plan has much the same impact as does raising employer match rates from 25 to $100 \%$ as illustrated in Figure I.C.2.

Bayer et al. explore which types of firms offer employee education programs, as a function of the plan types offered, unionization, employer matches, investment options, loan features, and participation rates. They conclude that seminars are more likely in larger firms and when a 
company has multiple plans, and less likely in unionized plans. The results indicate that education increases participation and contribution rates, and the effect is strongest among non-highly compensated employees as illustrated in Table I.C.2. The increase in participation rates for nonhighly compensated employees (NHCE's) is about twice that for highly compensated employees (HCE's), $12.1 \%$ versus 6.6\%. Contribution rates increase about $1 \%$ for NHCE's following seminars, but have no material impact on contribution rates for HCE's. These results are significantly stronger for seminars than for written plan materials, and frequent seminars increase participation significantly.

The importance of educating employees about their pension plan is corroborated by Bernheim and Garrett (1996) who use a 1994 Merrill Lynch survey of some 2,000 households. Here the authors explore the link between wealth and savings rates and various other characteristics of the respondents. Median regressions are used to alleviate the skewness in wealth distributions described above. What they find is that when retirement education is offered, it is strongly related to retirement wealth and savings flows, although not to respondents' total net worth. In addition, these education effects are more pronounced for those saving very little to begin with. Specifically, where education is provided, median $401(\mathrm{k})$ balances in pension plans are greater than where it is not ( $\$ 8250$ vs. $\$ 5000)$. The differential outcome is even greater when employees are divided according to whether they actually attended the educational sessions ( $\$ 10,000$ vs. $\$ 4000)$. Not only are balances higher; there is also a positive relationship between use of educational material and probability of $401(\mathrm{k})$ usage, such that those partaking of the pension education have $12 \%$ higher participation rates in the $401(\mathrm{k})$ plan.

The nature of Bernheim and Garrett 's database allows them to assess the spillover effects on other saving. Availability of retirement education increases overall saving by 1.65 percent, greater than the approximate one percent increase in targeted retirement saving. This indicates that education provides wholesale changes in saving behavior and not just small changes at the margin.

\section{Conclusion}

Although economists are just beginning to understand why people do not save adequately for retirement, it appears that there are some mechanisms at our disposal to improve matters. Tax inducements via IRA's, 401(k)'s, and other programs do seem to help, though there is still dispute about the precise degree to which they help. Recent changes to IRA contribution limits increasing deductibility for couples and proposals by the Administration to further raise contribution limits would provide natural experiments to help sort out the value of these deductions. Also of note is a pending bill to increase peoples' ability to borrow from their pension plan for needs such as mortgage down payments or college tuition. If implemented, allowing limited pre-59 1/2 
withdrawals may ease liquidity concerns among some households and hence increase saving (of course it also might lower eventual retirement balances).

The impact of employer sponsored financial education programs appears to be quite positive. The studies summarized here show that education has strong savings inducements especially among those plan participants with lower incomes, and these are precisely the households that need to be spurred on the most. We also find that the saving increases spill over to accounts outside of the employers direct sphere of influence. Education is seen to be a substitute for employer matching contributions. Therefore it may be more cost effective for employers to induce employee participation and contributions to plans by actively providing education.

There are two potential negatives associated with employer education. The first is coverage. A significant fraction of the workforce is not currently covered by employer sponsored plans. This is the population segment that arguably most needs financial education but there are no apparent benefits to these employers for providing it. The second negative is the threat of fiduciary liability; companies providing financial education take on some risk of participant complaints in the event of investment shortfalls. The legal issues surrounding this point are still under litigation, suggesting that employers will proceed cautiously on the financial education front.

It is important to note that both of the mechanisms just described address the symptoms of undersaving but not the underlying problem. Further study of the causes is warranted. It is likely that there is no singular driving factor, but that different households do not save for different and, possibly, individual reasons. Research into why people do not save and the variance in saving profiles should be a foremost priority.

\section{Asset Management Prior to Retirement}


Having described the asset accumulation procedure, the next question is how people invest their assets intended for retirement. In this section we explore a range of views on how investors should think about managing their portfolios prior to retirement, and in the next section we examine relevant data on how people actually manage their retirement saving. We show that - not surprisingly -there is a wide range of opinion regarding what asset allocation goals should be, and experts do not agree on what the optimal rule for allocation of retirement portfolios.

\section{A. Retirement Asset Allocation Goals}

A great deal of investment advice is proffered to investors by the large and growing industry of financial advice-givers. This group generally advises conservative investors to hold the majority of their assets in bonds, while aggressive investors are encouraged to hold stock. Four such recommendations appear in Table II.A. 1, ranging from Fidelity Investments (a large mutual fund company), Merrill Lynch (a large brokerage firm), Jane Bryant Quinn (a financial columnist), to the financial section of the New York Times (Canner et al. 1994).

Averaging the advice from these four representatives of the financial community reveals that investment advice offered varies with investor risk aversion. Should the investor believe himself to be risk averse or conservative, he is advised to hold about a third of his portfolio in bonds and another third in cash (or short term money market funds). This conservative investor would therefore have only about $30 \%$ of his funds remaining to invest in stocks. If the willingness to take on risk is higher, the investor is advised to hold more stock. Thus after consulting financial advisers, a moderately risk-averse individual would be expected to hold about $40 \%$ in stock, and an "aggressive" individual advised to hold $80 \%$ or more in stocks.

It is interesting that these asset allocation recommendations accord closely with Siegel's (1995:299) proposal that the optimal portfolio of a conservative investor should consist of $25 \%$ stock, a moderate investor's should include 50\% stocks, and a risk-taking investor's holdings should be 95\% stock. But Siegel argues that this recipe is "best" for investors with only a single year time horizon; since people saving for retirement have a far longer holding period than a single year, he argues that a better long term allocation would be much more concentrated in stock. Even a conservative investor planning on holding the assets for 10 years is advised to hold $40 \%$ in stock, and if more than 30 years, he advises $72 \%$ in stock. The aggressive investor contemplating either a lo-year or a 30 -year holding period is counseled to place more than $100 \%$ of investable funds in stock (borrowing against other assets to achieve this goal). Siegel's conclusion flows from his view that, in the long run, bonds and money market funds are likely to lose value due to inflation and be dominated by higher stock returns.

Notwithstanding the popularity of the advice that long-horizon investors should hold stock, some in the research community take issue with it. One concern is that people tend not to know whether they are conservative or aggressive investors, leading investment advisers to offer 
questionnaires that seek to elicit risk preferences (and ability to bear risk; see Hallman and Rosenbloom 1993). A simple solution is to link some simple observable characteristic about the investor - such as age - to (unobserved) risk preferences. This is usually the thesis behind the prescription that young people should invest in stocks, presuming that they have a longer time horizon and thus should be more tolerant of risk. One proponent of this view is Burton Malkiel, (1996: 411) who favors "more common stocks for individuals early in the life cycle and more bonds for those nearer to retirement".

The view that stocks are a better investment for the young is also challenged by a distinguished group led by Nobel-prize winner Paul Samuelson (1994) who argues that the decision to hold stocks versus bonds depends on a complex set of assumptions about the capital market as well as other assets the investor holds. In a recent review of the arguments, Canner et al (1994) concluded that in a world with a simple CAPM model, the optimal rule is for "all investors [to] hold risky assets in the same proportions" (p. 5; see also Jagannathan and Kocherlakota, 1996). In particular, all investors would be predicted to hold bonds to stocks in constant ratio of 0.3 throughout their lives and adjust portfolios to suit risk tolerance by adjusting the relative holdings of this stock-bond portfolio with cash holdings. This is a very different prescription than the fractions proposed in Table II.A. 1.

One reason financial advisors tend to deviate from the CAPM golden lifetime ratio of stocks to bonds is that risk averse investors are unwilling to face a 1929-type stock market crash. That is, even though in the long run investors might make more money holding a large fraction of stocks, this much stock exposes them to a potentially large loss of the type that would wipe them out. It simply might not be possible to borrow enough against the future in order to survive in the short run (Bodie 1995).

Another reason to deviate from the simple CAPM model's prescription is because people hold a great deal of their wealth in human capital rather than physical capital, particularly when they are young. So when deciding how to invest financial assets, what becomes critical is the anticipated future correlation between labor earnings and capital returns as well as the worker's remaining work life. If bonds were more closely correlated with salaries than stocks, for instance, then a young worker would hold more of his financial capital in stocks to offset earnings risk. Later in life when a worker's human capital was exhausted, he would reasonably switch to a portfolio heavier in bonds (Bodie, Merton, and Samuelson, 1992).

In sum, there are strong differences of opinion across financial advisers regarding what should be the desired level of equities, bonds, and other assets in peoples' portfolios. What is interesting is that after a great deal of research, it appears that the "folk wisdom" offered by financial advisers but rejected by some academics may now be revived. That is, though controversy lingers, the current view seems to be that stocks should be favored in retirement portfolios by 
younger people, and bonds by older people, at least for those whose earnings are correlated with bonds (Jagannathan and Kocherlakota, 1996).

Despite this conclusion, however, a great deal more research remains to be done to fine-tune asset allocation suggestions. In particular, advisers must begin by measuring and then taking into account other co-movements between earnings and returns on a wider range of capital flows workers receive. In this process we need to learn more about desired asset mixes in more complex circumstances. For example the asset allocation needs of a married couple where each works in a different industry and faces different retirement ages are likely to differ from those of a single individual; as Kotlikoff and Spivak (1981) have shown, risk sharing within the family can be quite powerful. Similarly, the implications of risk sharing across generations should be explored in more depth, where for example an anticipated bequest of a parental home could influence the adult child's desired asset allocation. Asset allocation patterns should also be devised to take into account liquidity needs that occur at predictable times - such as for children's college tuition. And as a final example, 401(k) retirement portfolio allocation decisions might differ a worker with no other financial assets, versus a second worker with a large defined benefit plan and a house. Research on these extensions has only begun.

B. How Do People Actually Invest their Retirement Assets? 
Having explored some of the practical and theoretical advice offered to investors, the next issue we tackle is how people actually invest their retirement assets. The question might be asked whether people seem to follow advice from the investor community, and if so, whether it influences their investment allocations.

Above we noted the fact that there is some controversy over what is, and what is not, properly counted as retirement assets -for instance researchers disagree over whether owneroccupied housing should be counted as retirement assets or not. In any event, for all but the wealthiest households, net financial assets other than housing are so low as to be virtually uninteresting from the point of view of examining asset allocation patterns. That is, despite the fact that the HRS cohort is on the verge of retirement, the bottom $20 \%$ of the earnings distribution has accumulated virtually nothing in the way of net financial assets (excluding housing) -- $\$ 3,000$. At higher income levels, nonhousing wealth rises, but to only $\$ 18,000$ for the second quintile, to $\$ 41,000$ for the third quintile, and still only $\$ 68,000$ for people earning in the fourth quartile (Table II.B. 1). Only in the top-earning quintile do the net financial holdings other than housing cross the hundred-thousand dollar threshold, for a median value of $\$ 165,000$. These figures do not include company-sponsored pension values, but do incorporate dedicated retirement accounts like IRA's and Keogh plans. As Table II.B. 1 shows, however, such dedicated retirement accounts have a median value of zero or close to zero for all but the highest earnings group, where even there the total accumulation is only $\$ 15,000$.

Because of the fact that net financial assets other than housing accumulations are so low even among the population closest to retirement, it is more productive to turn to an examination of company-sponsored pension accumulations to examine retirement asset allocation patterns. In this context, it is necessary to distinguish between defined benefit plans, where employers normally have the sole responsibility and control over asset allocation decisions, and defined contribution plans, where participants are normally able to influence the way their accounts are invested.

It has long been conventional wisdom that defined benefit pension plans tend to hold far more of their portfolio in equities than do defined contribution pension plans, perhaps because of the expectation that individual participants are more risk averse than are group pension trustees. However a glance at Table II.B.2 indicates how wrong this common perception is, as evidenced in several recent studies on pension fund holdings. Specifically, assets held in large single-employer defined benefit pension plans are about half in equities, a fraction not very different from the current holdings of defined contribution plans. Of course, the figures depend somewhat on when the data were collected and by which group: for instance, a Greenwich Associates survey of large corporate pension plans found equities amounted to $47 \%$ of private defined contribution pension holdings and 57\% of the defined benefit funds in 1993, while a 1996 survey of the top 1000 corporate plans by Williams (1997) found the DB/DC equity fractions more similar, at $48 \%$ and $53 \%$, 
respectively. Nonetheless the message is one of similarities rather than discrepancies: equities rose and fixed income holdings fell, with $33 \%$ of defined benefit assets and $30 \%$ of defined contribution plan assets in bonds and other fixed income holdings in the most recent data.

Based on this findings it seems that excessive conservatism among defined contribution investors is currently not a matter for substantial concern. Overall, in fact, the results suggest that defined contribution asset allocation patterns are roughly consistent with those suggested by the financial press for the moderately risk averse investor described above. One reason that this might be true now, thought it was less true in the past, is that participants in defined contribution pension plans have moved away from guaranteed investment contracts over time. Thus between 1990-1996, GIC representation fell from $29 \%$ to $21 \%$ of defined contribution assets (Williams 1997). Another reason for the higher-than-anticipated current concentration of stocks in defined contribution pension portfolios is that “[a]s the stock market rises, participants don't necessarily rebalance their 401(k) asset allocations the way pension executives rebalance defined benefit plan allocations" (Williams 1997: 1). This suspicion is confirmed with a glance at the EBRI figures in the table: in 1983 the typical large DC pension held 39\% of the fund in equities and a decade later the fraction had risen to 45\%; similar patterns hold true for the Williams data. By contrast DB equity holdings either held constant or fell slightly, according to the EBRI and Williams survey information.

A more detailed investigation of this conclusion is warranted since averages conceal important details. For example, knowing whether asset allocation patterns differ across the population according to sociodemographic traits might be a first step toward asking whether these patterns are intentional or accidental.

Preliminary information on this is provided in a study by Schieber and Goodfellow(1995), who draw on a datafile covering 24 large private employers with pension plans covering 36,000 employees. The results in Table II.B.3 reveal that 401(k) asset allocation patterns change with plan participant age rather dramatically. For instance, workers over age 60 hold little of their retirement portfolio in equities - under $15 \%$-while people younger than 40 buy stock or stock funds with close to half of their 401(k) money. The all-employee average for the sample was $34 \%$ of assets held in stock, including stock funds, company stock, and international stock funds. (These percentages are exclusive of stocks held in balanced funds since there are no data to back out stock holdings in these plans.) The overall inverse relation between age and equity holding suggests less risk aversion among the younger population, though even people in their 40's were found to hold as much as $40 \%$ in equities in their $401(\mathrm{k})$ plan, Conversely, assets held in fixed-income investments rose from about $40 \%$ for people in their 20 's, to more than double that for people over age 60 . In other words these data indicate asset allocations vary by age in the direction predicted by the theoretical approaches to asset allocation identified in the previous section. 
Another way to examine the asset allocation decision asks how investment strategies change with participant earnings, a pattern indicated in the second panel of Table II.B.3. The data show that the average employee devotes half his pension contribution to stock funds, or as much as $60 \%$ on equities if the other two stock categories are included. Interestingly, those earning up to $\$ 60,000$ put at least half of their investments in balanced income funds; only those in top brackets (earnings $>\$ 60 \mathrm{~K}$ ) invest less than half of their money in the balanced fund (and instead emphasize pure equity funds). Fixed income holdings represent a relatively small portfolio fraction, never above $20 \%$, but rise with pay. The low-paid group is less likely to invest in any form of corporate stock than higher paid people, yet the lower-wage group still devotes a third of the portfolio or more to stock. Of course, this might be perfectly in line with the notion outlined earlier - that high earners buy equities early in life and bonds later to offset depreciating human capital, while low earners would have no particular reason to buy equities to offset human capital risk.

A different cut on the data is to look at asset allocation patterns by sex, which differ rather sharply by economic sector, as depicted in Tables II.B.4 and 5. The information in Table II.B.4 is drawn from a recent survey of $401 \mathrm{Q}$ plan participants who were employees of large firms operating across a range of different industries. These data are nonrepresentative of workers in smaller firms, but no better data on asset allocation practices in private plans are available by sex. It is interesting to observe that in this survey, at least, women and men seem to behave quite similarly: pension accumulations as well as new contributions devoted to equities stood at about $50 \%$, and

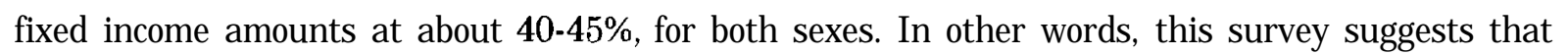
plan participants in the private sector $401(\mathrm{k})$ pensions are following the "moderate investor" advice recommended in Table II.B. 1 quite faithfully.

A quite different pattern is evident in a recent survey of asset allocation patterns by sex among Federal Government employees investing their Thrift Saving Plan holdings. (The TSP plan is similar to the $401(\mathrm{k})$ offering available to private sector employees). In the TSP, all employees are required to hold some funds in the government securities fund [G], but may elect the fraction of funds invested in the stock and/or the bond index funds offered. In 1994, the data show that only $28 \%$ of the women versus $45 \%$ of the men opted for the equity index fund, and women held only $9 \%$ of their assets in the equity fund (versus $15 \%$ of men's assets). Women in the TSP also were slow to move into the bond fund: 12 percent versus $20 \%$ of the men had chosen to invest in the bond fund. Women's reluctance to diversify out of the G fund lead Hinz and Turner (forthcoming) to estimate that men would end up with retirement portfolios worth four to 16 percentage points more than similar women (simply as a result of having invested in lower-return, lower-risk holdings - See Table II.B.6.). One question that has yet to be addressed is why both male and female Federal sector employees are less likely to buy equities with their pension contributions than do their private sector counterparts. A second issue is why women in the Federal sector appear to be more 
conservative investors, across plans. It is possible that Federal employees' total compensation is more correlated with stock returns than the average private sector employee - and female civil servants' pay is even more correlated thus -but this seems doubtful. Alternatively the Federal sector may attract more risk-averse workers, particularly among women, than average. Both hypotheses could be tested given the right dataset.

\section{Factors Influencing Asset Allocation Patterns}

The results described in the previous section offer descriptive tabulations of asset allocation patterns by age, sex, and pay, but do not hold other factors constant that might alter measured effects in multivariate models. In this section we turn to an analysis of what has been learned in a multivariate context, and what remains to be learned.

One problem plaguing research in this area is that few analysts have had the requisite microeconomic data needed to empirically hold constant a range of sociodemographic and firm-side factors indicating how savers allocate assets in their retirement accounts. Understanding what factors influence employees' asset allocations in their portfolios in a multivariate context requires good data on workers' income level, age, sex, pay, education, and sex, as well as wealth and portfolio allocations. In addition, it would be useful to gain a deeper understanding what potential "policy tools" are that would influence asset allocation decisions in retirement accounts.

A recent effort in this direction was undertaken by Kennickell et al. (1996) using a nationally representative dataset on about 4,000 households examined in the 1983 Survey of Consumer Finance. Respondents to this extensive questionnaire were asked questions regarding whether and from whom they sought financial advice, which could then be linked with information on the households' retirement assets and other wealth holdings. Specifically the SCF question posed was "How do you (and your husband/wife) generally decide what kind of saving and investments to make - do you get help from an accountant, a banker, a broker, a tax advisor, a lawyer, a friend or relative, or what?" (Kennickell et al. 1996). The fmdings, summarized in Table II.C. 1 , show that only $45 \%$ of the 4,000 nationally representative households questioned sought financial advice. Of those, the vast majority - 57\% - obtained information from relatives and friends. Only a quarter of the people contacted a financial professional for financial advice, including bankers (26\%), brokers and accountants (17 and 14\%), and tax advisers and lawyers (9 and $11 \%$ respectively). Differences by income level are probably not surprising: people earning $\$ 25,000$ or less were far more likely to consult friends and relatives than average, while higher-paid respondents were much more likely to go to brokers, bankers, and accountants. (Similar differences were observed by wealth level).

Responses about peoples' sources of advice were then linked with data on their financial portfolios, while holding constant a range of other factors including age, education, earnings, sex, ethnicity, retirement and marital status. The net effect of different types of advice on three 
outcome measures was then measured, focusing on how diversified the households' assets were, the household's overall level of saving, and what fraction of household assets was devoted to stock. The authors arrived at the following conclusions (Kennickell et al., 1996):

- Households indicating they obtained any financial advice were more likely to have more types of financial assets. The positive effect of friends/relatives and brokers on diversification was stronger than for other types of advice.

- Households that reported using financial advice, particularly those that relied on friends and relatives, had saving rates that did not differ from non-users. Those consulting brokers had higher than average saving rates; in some models, people who used bankers and lawyers had lower than average saving rates.

- Households getting financial advice tended to hold $25 \%$ more assets in stocks and mutual funds, and the positive effect was strongest for those working with brokers. ${ }^{17}$

Why people obtaining financial advice should save differently, and in particular why brokers should have the strongest effect on saving rates and asset diversification, remains to be determined. A possible explanation for the phenomenon might be that brokers are able to explain risk and return patterns to financially naïve investors in a way that influences their investment patterns. In a recent case reported by Benartzi and Thaler (1996), newly-hired staff members at a California university were presented with a questionnaire giving two different formats for data on their 401(k) investment options. In both cases respondents were asked to select the fraction of assets to invest in "Fund A" versus "Fund B" after being shown a chart with historical rates of return under the two funds. Participants were not told in advance that Fund A returns were actually derived from simulations of an index of value-weighted stock returns and Fund B returns were derived from Ibbotson's annual returns on 5-year bonds. The difference between the two cases was how the researchers presented data on each fund's returns. In the first scenario, one-year returns were arrayed from best to worst, and in the second scenario, 30-year holding periods were arrayed in the same fashion. In the first scenario, the median allocation to the stock fund was only $40 \%$-- because respondents fastened on the fact that Fund A had experienced negative $40 \%$ returns at least once. In the second scenario, the median stock allocation rose to $90 \%$, because respondents realized that over all 30-year holding periods there was a small chance of only a small negative return. Hence the psychological research strongly suggests that different data presentations on risk and return dramatically alters peoples' portfolio allocation results, and it may be that brokers have been the most adept at discerning this in the recent past.

To examine this point in more detail, Figure II.C. 1 presents a similar scenario to the experiment from the Bernatzi and Thaler study. The two panels show the results of simulating

17 Point estimate supplied in personal communication. 
draws from historical stock and bond data for the seventy year period 1926-1995. ${ }^{18}$ For the l-year return simulations, real returns on stocks range from a low of $-37.4 \%$ to a high of $53.4 \%$, with a mean of $9.4 \%$ and a standard deviation of $20.4 \%$. Real returns on bonds are lower on average at $2.7 \%$, but are more tightly distributed - ranging from $-15.5 \%$ to $35.1 \%$ with a standard deviation of 10.6\%. The returns exhibit no discernible pattern with some instances of both extremely good and extremely bad stock returns.

The second panel shows the results of simulating returns over alternative 30-year holding periods, from the annual data; we then annualize the longer returns. The results suggest that stocks "dominate" bonds - the mean and a substantial portion of the mass of the simulated stock return distribution is to the right (higher returns) than the simulated bond distribution. For the stock distribution the mean annual real return is $7.3 \%$ with a standard deviation of $3.8 \% .{ }^{19}$ The lowest of the 10,000 simulated values is $-6.6 \%$ and the highest is $21.9 \%$. For bonds the corresponding mean and standard deviation are $2.0 \%$ and $1.9 \%$, respectively, and values range from $-4.3 \%$ to $9.5 \%$. The return distributions have a familiar bell-shape resembling normal distributions.

People who argue stocks truly "dominate" bonds in the long run (e.g. Siegel 1995) base their argument on an apparent inter-temporal diversification. While there is much to be said for this case, a few caveats should be noted. The first of these centers on how the distributions of 30 year returns are calculated. In our table, for instance, the 10,000 simulated 30-year histories are effectively assuming that 300,000 years of return data are available for analysis. Of course this is not actually the case; instead only a 70-year history is available on market data, containing but two non-overlapping 30-year samples.

Another issue is that of rebalance risk and default or business-failure risk. All simulations such as these use annual return data, which may be appropriate for a stock portfolio which is rebalanced periodically. Even traditional benchmark indices such as the Standard \&Poor's 500 (SP500) or the Dow Jones Industrial Average (DЛA) occasionally drop older stocks and replace them with new ones. Rebalancing however is harder to justify for long government bonds. The return on a bond is a combination of the coupon payments and fluctuations in the price of the bond. If bonds are held to maturity (which is likely for households), the volatility in returns is significantly reduced. If held to maturity, US Treasuries carry negligible default risk. The same

18 Data are from annual returns from the Center for Research in Security Prices (CRSP) SBBI file. Stocks are represented by the total (capital gains plus dividends) return on the S\&P 500. Bonds are represented by the United States Treasury Bond total return. Returns are deflated by the annual change in the CPI.

19 It may seem odd that if the annual average real return for stocks from the SBBI data is $9.2 \%$, that the average annualized return from a 30 year return history is only $7.3 \%$. This is a result of Jensen's inequality, which states that for a concave function the expected of the function of a random variable is less than or equal to the function of the expectation of the random variable. $(\mathrm{E}[\mathrm{f}(\mathrm{X})] \leq \mathrm{f}(\mathrm{E}[\mathrm{X}]))$. 
cannot be said for individual stocks, or in some cases, entire stock markets. This is known as the "survival problem", examined by Brown, Goetzman, and Ross (1995) who show looking back at return data on the winners imparts an upward bias to return statistics. Over long periods this may be a very real problem for stock returns. The return history for the original portfolio of securities held in the DJIA or the SP500 may tell quite a different story than the rebalanced indices.

In the next few years there will be much opportunity for useful work in this field, as new data become available with which to explore the question of how assets are allocated and what influences this decision. Clearly one critical issue is how to measure investors' tastes for risk and how these shape the portfolios they seek to hold. The Health and Retirement Study mentioned above has included several experimental modules over the years designed to get at respondents' underlying risk aversion parameters. Whether these prove to be useful predictors of asset allocation outcomes is a subject for future study, along with an investigation of whether these are stable over time.

A different set of issues has to do with how sensitive investors are to changes in the external environment. Factors potentially driving household asset allocation patterns are many, including current and anticipated future taxes (e.g. capital gains taxes, the tax treatment of pension contributions and interest on home mortgages), prices and costs (e.g. interest rate effects on housing prices, administrative charges associated with different asset portfolios), inflation (e.g. the potential role of indexed bonds), and perceptions of stock market performance. It is fair to say, however, that the study of how these multivariate factors affect saving levels and asset allocation within saving portfolios is as yet in its infancy. ${ }^{20}$ The same conclusion applies to retirement assets as a subset of households' overall assets, as well.

\section{Conclusions}

While earlier sections asked what factors seem to influence retirement saving levels, this section has sought to examine how people invest the assets they do have control over. One important conclusion is that this is a relatively new field, about which a great deal more remains to be learned. Researchers have been severely handicapped because they lacked good data on household asset accumulation patterns and asset holdings as well as other pertinent information about preferences and constraints. These limitations have begun to be relaxed recently with new datasets, and researchers are now moving into the field with enthusiasm.

We also conclude that there are strong differences of opinion across the business and research communities regarding what mix people should hold in terms of equities, bonds, and other assets. If anything the so-called folk wisdom suggests that people should hold assets such as stock in their youth inversely correlated with their human capital, and move to less volatile holdings later

\footnotetext{
20 For an excellent recent review of the determinants of saving see Browning and Lusardi (1996).
} 
in life. This pattern appears to hold in the real world, with younger participants in private sector defined contribution or $401(\mathrm{k})$ pension plan having 50 to $60 \%$ of their funds in equities, and older workers being typically less heavily invested in equities. Public sector employees are found to hold fewer equities, as do women workers as a rule. Some of these patterns may be due to risk aversion patterns that vary across workers; other patterns may be attributable to financial advice offered by brokers. The fact that most Americans fail to obtain investment advice from informed sources indicates a substantial need for additional financial literacy.

\section{The Process of Retirement Asset Decumulation}

In previous sections we addressed the question of how consumers build up savings that they can then chose to consume in retirement. In this section, we turn to an examination of the asset decumulation phase, and ask how people are handling this process.

\section{A. Targets for Asset Decumulation}

It is reasonable to ask at the outset what the goal of asset decumulation over the retirement period should be. If lifespans and income as well as consumption streams were predictable, the simple life cycle model would imply that a rational and far-seeing retiree should draw down wealth steadily so as to maintain consumption, exhausting his asset stock just at death. At that date, the only assets remaining would be those intended to be passed on as bequests. Therefore a testable implication of this model is that older people would be expected to consume more than their income. with declines in wealth funding the difference. One might also anticipate that dissaving would be greatest among childless older people, and least among older persons planning on leaving an inheritance to their children. These implications have been tested in a range of empirical studies, as we shall show below.

Before turning to the evidence, it is important to recognize that economists realize that older people do not live in the certainty world just described. Retirees face an unknown date of death, uncertainty about human, financial, and physical capital, and substantial uncertainty about future paths of government and family support opportunities. They also confront tremendous risk in terms of future inflation and what this does to their retirement wealth.

Accordingly, theoretical research has worked to incorporate these key aspects of uncertainty into a more richly formulated life cycle framework in recent years. Unfortunately, these modeling efforts yield few clear-cut testable implications about anticipated wealth decumulation patterns in old age (Browning and Lusardi 1996). For instance, if people face a substantial risk of needing expensive nursing home care in old age, they may rationally save more to protect against this cost. This would imply very little dissaving among the elderly, particularly for the younger half of the cohort; conversely the older half of the cohort would be likely to have much larger nursing home expenditures and dissave quickly. 
At the same time, of course, peoples' saving decisions interact with government support programs for the indigent. For example, eligibility criteria for Medicaid induce some to consume all their assets in order to qualify for government-subsidized nursing home coverage. As a result this policy probably encourages more rapid dissaving among the younger half of the older cohort than would otherwise be the case. But the fact remains that adding important uncertainty to life cycle saving models injects so much complexity that there are few testable predictions about expected saving/dissaving in old age from these theoretical studies. About the most precise prediction that can be offered is that virtually no model would predict older peoples' assets to continue to grow during retirement; whether they decline or remain roughly constant is not theoretically predicted.

\section{B. The Facts About Retirement Asset Decumulation}

Understanding what drives saving and dissaving has been a central goal of the economics literature at least since Lord Keynes, yet investigation has been slowed by a formidable obstacle lack of good data. Most countries including the US produce annual macroeconomic statistics on total household and national saving, but these data are controversial due to questions about accuracy and probable underreporting. Aggregate saving data are also not terribly helpful in terms of understanding which kinds of people save, how much they save, and what influences these saving patterns.

For these reasons, household level data are preferred for behavioral analysis, where individual families are canvassed on their income and expenditures, assets and debts, and other information on their consumption needs and expectations about the future. This latter type of survey has begun to be developed and fielded in the United States only recently with the Health and Retirement Study. Because the HRS is intended to be longitudinal - people are reinterviewed every two years for the foreseeable future - the survey can hope to accurately estimate changes in asset levels (saving or dissaving) as respondents age. This is a costly survey to undertake, requiring long-term follow-up before good data on life cycle saving patterns can be teased out of the information; early results are available only from the first two waves (1992 and 1994). The AHEAD study (Assets and Health Dynamics of the Oldest Old) focuses on people age 70 and older, affording a unique opportunity to evaluate changes in assets of those in the second half of the retirement period. Other studies such as the Survey of Consumer Finances (SCF) do not follow the same households though time longitudinally, though they do offer useful information on assets and liabilities as well. Because of the fact that the needed data to do the analysis is only now becoming available, it is not surprising that there remains so much to be learned about wealth accumulation and decumulation in old age,

In exploring the evidence on wealth decumulation patterns in old age, two questions are of primary interest. First, we ask how older people draw down their "bequeathable wealth" as they age. By bequeathable wealth we mean to include all non-annuitized wealth that could in principle 
be passed on to someone else (Kotlikoff and Spivak 1981). This approach therefore focuses on relatively liquid assets such as checking/saving accounts, mutual funds, stocks, bonds, housing, IRA's and lumpsum rollovers from previous pensions, etc. It takes as given the household's split between annuities (social security and other annuities not included in bequeathable wealth) and all other sources of wealth. The second question then asks how older people divide their assets between bequeathable and non-bequeathable wealth. We take up each in turn.

\section{Financial Wealth Decumulation Patterns}

Turning to the first issue, the question is how do older people spend their financial wealth stock as they move through the retirement period. One crude way analysts have attacked this question is to correlate dependency rates and private saving using cross-country analysis. The evidence suggests a negative effect - that is, having a larger fraction of elderly reduces private saving rates -but controversy remains over how big this relationship is, ranging from nil to quite large in the set of studies recently summarized by Disney (1996). ${ }^{21}$

More persuasive to some is evidence from microeconomic data that also finds people dissaving as they age. The studies reviewed in Table III.B. 1 imply that wealth falls with age for the elderly, particularly so among single people without dependents (who are least likely to be interested in leaving bequests). The range of average annual financial wealth spenddown is $2.4 \%$ per year, higher for the childless and lower for those with dependents. Whether this wealth drawdown follows a smooth or a bumpy trajectory is as yet to be determined, though recent UK data suggest that older peoples' financial wealth declines quickly right after retirement, remains constant until a dozen or so years into the retirement period, and after that point dissaving sets in again (Disney 1996).

Assessing whether this rate of spenddown is "too large or too small" depends on a wide range of economic factors including among other things, how long the retiree anticipates living, what discount rate he or she uses, and what assumptions are made about financial market returns on one's bequeathable wealth holdings during the retirement period. (Taxes should also be taken into account, of course). It also depends on how much annuity or income support benefits the retiree anticipates receiving. In other words, one might be interested in computing the size of the "programmed withdrawal" from financial wealth that would smooth a retiree's income flow in old age, so as to determine what standard of living that retiree asset accumulation would generate.

To illustrate the concept we have undertaken a schematic calculation of this nature in Table III.B.2 for the median HRS respondent household. The goal of the computation is to determine the

21 Even less clear is what the effect of an aging population is on national saving as a whole, since this effect depends on government expenditures on the aged - particularly social security - and these programs are generally unfunded pay-as-you-go systems that are perceived as reducing national saving (Disney 1996). 
annual income flows that could be generated using a programmed withdrawal methodology similar to that propounded by the IRS in drawing down Individual Retirement Accounts. It should be noted that the programmed withdrawal approach does not avoid the possibility that the retiree outlives his assets; it is not a life annuity. Table III.B.2 summarizes the findings by showing that the median HRS household following a programmed withdrawal approach from net financial assets would have a very modest income stream in retirement, abstracting from pensions and social security benefits payable in retirement. Specifically, annuitizing the median financial wealth of approximately $\$ 100,000$ over a two-person household (the norm in the HRS) for the retirement period generates a real annual flow of $\$ 5500.22$ Compared to pre-retirement average income, these annual flow values are sufficient to provide only a very small replacement rate - exclusive of other benefit programs.

One reason that this pattern of spenddown may be deemed low is that people have alternative assets that could be used in the event of need, including sale of their house (to be discussed next) and annuity income flow (to be discussed below). Another reason is that at least some portion of the population may want to leave a bequest, most likely those with children. In Table III.B.3 we tabulate responses to questions from the HRS in which respondents indicate their intention to pass on bequests to their children. It is interesting to note that wealth appears uncorrelated with intention to leave an inheritance. However, the expectation of leaving an inheritance is increasing in wealth. We interpret this to mean that older people who expect to leave a bequest do so only if they have accumulated substantial wealth by a particular point in their lives, but they do not seem to save in order to leave a bequest.

\section{Housing Value Changes in Retirement}

Because housing constitutes such a large portion of elderly American's net worth, it is important to ask whether people decumulate housing assets in old age to help finance consumption. The answer seems to be that in the US at least, past retirees have not released home equity by moving to smaller, less expensive homes, nor have they availed themselves of reverse annuity mortgages, a financial product designed to unlock home equity for older homeowners wishing to access their cash without moving out of their homes. As a result, some experts have argued that older people hold "excess" housing, and advocate developing mechanisms to help release this excess (see Disney 1996). On the other hand there are technical problems with doing so, including the possibility of adverse selection (mainly the long-lived will seek to purchase the reverse annuity) and the fact that home depreciation and loss of value is a problem faced by older people's housing stock (for a list of references see TIRS 1995). In any event, the size of the annuity that would thus be generated tends to be quite small at least until the age of 75 (Skinner 1993).

${ }^{22}$ This abstracts from insurance loads charged by annuity vendors; see Mitchell, Poterba and Warshawsky (1997). 


\section{Evidence on Annuitization in Retirement}

The discussion thus far has focused on the question of older persons' drawdowns of financial assets described above as bequeathable (i.e. not annuitized). Next we turn to the question of how much of household wealth is, in fact, available to be drawn down, and how much is only available as an annuity payout. As was previewed above, many retirees have little if any financial wealth at all, reaching retirement with only a Social Security entitlement. Under current law, this entitlement cannot be borrowed against, nor taken as a lump sum. (It should be noted that some recent Social Security reform proposals would allow retirees access at least part of their social security accounts; see TIRS 1995).

What about other sources of income flows? Among HRS respondents about half were entitled to an employer-provided pension benefit (See Table I.A. 1.). In keeping with the overall changes underway in the US pension environment, retirees in years gone by tended to be covered mainly by defined benefit (DB) plans, but increasingly workers and then retirees are owed a defined contribution (DC) entitlement. Not only have plan types changed, but features of existing plans have also adapted to competitive pressures. Thus until recently DB pensions required retirees to take an annuity payout, but in the last decade employer surveys show that they are allowing eligible retirees to receive increasing portions of their benefits in lump-sums at retirement (McGill et al. 1996) Of course in DC plans, lump sum cashouts have always been the norm, according to the same plan-level surveys.

One question that has not been well-researched yet is how pension-covered workers are responding to the new availability of pension lump sums. Policymakers' concern has been that people might pervert the intent of the pension system by "blowing the money" on unneeded consumption. To discourage this type of behavior the federal government has levied an excise tax on pension funds distributed before the recipient is age 55; someone withdrawing his fund early pays this penalty plus income tax on the amount. Empirical analysis of the effect of this excise tax has found that most recipients at low income levels are not deterred much from cashing out their lump sums, though for higher income workers a one percent increase in the excise penalty led to almost half a percent fewer rollovers (Chang 1995). It also appears that the higher the value of the pension lump sum amount, the more likely a participant is to roll it over into a tax qualified account rather than spend it (McGill et al. 1996).

Another issue is how the lump sums available from pension plans are invested during the retirement phase. Virtually nothing is known about this question at present, and it would be most useful to devise a nationally representative dataset capable of addressing the issue in the immediate future. Anecdotal evidence suggests that most workers given the option to take cash from their pension accounts are taking the cash rather than purchasing life annuities through group retirement plans. This is surprising in that a life annuity provided through one's employer would 
tend to be priced at group rates below those offered to individually-purchased annuity buyers (for adverse selection reasons as well as because of scale economies). The size of the group discount would of course vary with group characteristics; on the other hand, inasmuch as individually. priced annuities devoted $10-15 \%$ of assets to administration and overhead costs (Mitchell et al. 1997), this is more than double the group annuity cost figure offered by industry experts. The cost advantage of buying an annuity product through a group should be examined more fully by those seeking sensible ways to decumulate retirement assets.

When thinking about annuity issues there is another issue that needs to be more fully recognized, which is that people seem to be increasingly likely to buy guaranteed period certain options rather than simple life annuities. This is evident in a recent survey higher education faculty and researchers covered by the TIAA-CREF pension system (Hammond forthcoming). What was striking about this study was that, over time, participants have grown increasingly likely to select lo-year and 20-year certain options rather than single life annuities as was the norm in the past. In addition, people tend to hold their defined contribution accruals as a variable annuity into retirement rather than taking a fixed benefit, notwithstanding the additional capital market risk imposed on the retiree by this strategy.

Putting these trends together, it appears increasingly likely for pensioners to lay claim on part or all of their pension assets without annuitizing them, in contrast to years past. If this trend continues it suggests that ever larger segments of retiree wealth will move into the nonannuitized, and potentially bequeathable category; this will place increasing responsibility on retirees to manage the decumulation phase more carefully than ever before.

\section{Factors Influencing Retirement Asset Decumulation Patterns}

Several factors are likely to influence asset decumulation patterns in retirement. Among the most prominent would presumably be people's expectations about the future - their own anticipated longevity, the probability of poor health and the need for nursing home care, and future macroeconomic variables including inflation and interest rates. In addition people's risk aversion and discount rates would be expected to influence how the form in which they hold retirement assets, and how quickly they would draw down their assets in old age.

Relatively few surveys to date have elicited data on expectations of this sort. One innovative exception in this regard is the HRS, which asked respondents about anticipated life expectancy, inflation rates, and (for a subset of people) risk aversion and discount rates. These data have just begun to be examined to see whether these expectations are correlated with respondents' asset draw-down patterns; more additional research remains to be done. An interesting finding thus far is that respondents seem to have a quite accurate estimate of their own life expectancy based on a comparison of self-reported longevity probabilities with actuarial life tables (Hurd and 
McGarry 1995). Specifically, both men and women between age 51 and 61 seem to assess the chances of survival to age 75 and 85 relatively accurately.

Also of interest is the finding that those expecting to live longer than average have accumulated more than average assets, indicating a link between anticipated retirement periods and saving. Future research will be able to determine whether those expecting to live longer than average also handle their asset decumulation differently - for example, by drawing down their wealth more slowly, by buying annuities, and by having pensions of the DB rather than the DC variety. Research on people's anticipated health problems, forecasts of macroeconomic variables, risk aversion, and discount rates has not yet gotten very far, but it is anticipated that similar research questions would be highly useful.

A related issue has to do with what people expect regarding their future retirement program payouts and how these expectations influence their net financial wealth holdings. One of the unusual and interesting aspects of the HRS study is that respondents were asked what they anticipated receiving from their employer pension (if they had one), and from Social Security. These benefit expectations can then be compared with benefit amounts computed using administrative records from employers and the Social Security Administration, so as to judge how accurate retirees' estimates are. ${ }^{23}$ Yet to be tested is the hypothesis, for instance, that respondents who prove to be overly optimistic about their pension and social security benefits are those who undersaved when young, and overconsume their retirement assets when old. One might also expect the overconfident to be more liquid and less annuitized in their retirement portfolios than other retirees.

Clearly there are several other factors influencing asset decumulation patterns, including the relative price of holding different assets and unwinding them. One important issue is the cost of annuities available for purchase in the marketplace. Notwithstanding the claim made by previous studies that the annuity market is quite imperfect, recent research (Mitchell et al. 1997) concludes that individual annuity values are actually quite favorable compared to their price. In other words, adverse selection and insurance loads have declined over time, making this insurance product much more favorable to retirees now than in the past.

Taxes and government benefit programs also play a powerful role in asset decumulation patterns in old age, yet thus far relatively little is known about how sensitive people are to these programs. It is known, for instance, that people greatly understate the probability of needing and the cost of nursing home care, perhaps because they mistakenly believe that Medicare will pay for it. Instead, nursing home care in the US is available only through Medicaid, which is a meanstested program requiring older people to exhaust their assets before becoming eligible for

${ }^{23}$ Access to the administrative records is available only under special restrictive circumstances; see the HRS/AHEAD internet site for further information (www.umich.edu/ hrswww). 
government-paid nursing home care. Irrespective of which program older people have in mind, it is alleged that many near the Medicaid asset threshold spend down their assets more rapidly than they would otherwise so as to receive the coverage (Davis 1996). How potent this effect proves to be empirically awaits further testing with newly available datasets. To the extent that eligibility for other benefits is also conditioned on assets and/or income (e.g. housing subsidies, food stamps, disability benefits), these other programs could have similar effects on asset decumulation behavior. A great deal remains to be learned about these potentially complex interactions between government programs and private behavior.

\section{Conclusion}

Cross-national studies generally show a small negative association between private saving and the fraction of the population that is elderly. Microeconomic studies of older Americans using longitudinal data suggest that older people dissave but only very gradually, at least until age 75 or so.

A more detailed examination of these patterns will soon be possible with the two new datasets under development. Researchers are on the verge of major new breakthroughs in understanding patterns of asset decumulation in retirement. In particular, the HRS and associated administrative databases will now enable analysts to explore retirement decumulation patterns in a way not previously possible, linking financial, housing, pension and social security wealth to a range of questions about expectations and attitudes toward risk. The AHEAD database, since it focuses on somewhat older people, will also offer a vitally useful longitudinal picture of how older peoples' health problems influence their retirement assets, and will help identify where older people appear to be underinsured in old age.

While there is much to learn about what influences asset decumulation in old age, there are also lessons to be gleaned from past studies. We have argued here that retirees are able to lay claim on increasingly large fractions of their retirement assets without annuitizing them, in contrast to years past. This is placing growing responsibility on retirees to manage the decumulation process carefully, more than perhaps ever before.

Looking ahead, it appears that many of the factors that induced older people to keep their wealth in bequeathable form will be changing in the future, probably in the direction of enhancing the private demand for annuities. The best available evidence suggests that the transition from DB to DC pension plans will continue, meaning that ever fewer people will be guaranteed a pension annuity stream for life. As this happens, more people will seek out a means to protect against outliving their retirement assets. Another pending reform is the possibility of social security benefit cuts which if it occurs will also increase the demand for privately purchased annuities as the government's role declines. If the private insurance market continues to offer competitive returns 
on the annuity premium dollar, this too is likely to enhance the product's attractiveness. (Increases in anticipated life expectancies would both increase demand and raise the product's cost.)

Some factors could, of course, work in the opposite direction. For instance, of Medicaid and Medicare benefits were substantially cut back, people would be exposed to more substantial medical care bills. This might lead them to avoid annuitizing in order to have assets sufficient to cover a period of time in a nursing home should the need arise. This would also produce some substitution between long term care insurance and annuity insurance, unless insurers could design a new contingent product that covered both nursing home risks and longer than expected longevity (Disney 1996). And as we have mentioned, if public annuity benefits were to decrease in importance, older parents may become more aware of the need to save more and hold these savings as bequests, as an "inducement" to get children to deliver health and other care in old age.

\section{Lessons and Implications}

The goal of this study was to review what is known about retirement asset accumulation and decumulation to assess whether Americans are doing a reasonable job of preparing for retirement, and spending down while in the retirement phase.

Part I of the analysis examined wealth accumulation patterns. Relatively little is known about this area because of the extreme difficulty obtaining high quality data on household assets and liabilities, but new surveys including the Health and Retirement Study have made it possible to add to knowledge rapidly in this field. In our analysis we defined several different wealth measures and compared accumulated values with a range of benchmarks often used in assessing retiree wealth adequacy. On the basis of the best available data, we conclude that the median American on the verge of retirement has accumulated too little wealth to support a comfortable retirement. To achieve widely agreed-on retirement accumulation targets, a typical household with a head in his or her mid-50's would have to set aside $23 \%$ of income between now and age 65 to achieve a replacement rate consistent with what retirement planners have recommended.

Part II of our investigation examined how people invest their assets intended for retirement. Rules of thumb advocated by financial advisors typically recommend that the moderately riskaverse investor hold $40-50 \%$ of his wealth in stocks and the rest in bonds. More complex models recommend altering the mix of stock and bonds over the work life, depending on the investor's human capital characteristics. When we examined actual household allocations of financial asset holdings, however, we found that most Americans hold relatively few financial assets (excluding their homes). The median older household age 51-61 has only about $\$ 40,000$ in net financial assets excluding company pension plan accruals, certainly not enough to hope to live well for 15-20 years or longer in retirement. For this reason we focused in more detail on assets accumulated in company sponsored pension plans, where we saw that the typical defined contribution participant 
appears to have selected a portfolio quite in line with the financial advisors' suggestions. It appears that among younger workers in particular, it is now common to see participants hold $50-60 \%$ of their assets in equities; even among low-wage workers, about a third of the pension portfolio goes to stock purchase. The one area of some concern is that women employees are much less likely than men to invest in stock in some pension systems, a finding that may produce lower-than-desired benefit amounts in retirement.

Further delving into what is driving these investment patterns revealed some interesting patterns. Specifically, households derive relatively little financial advice from financial experts, relying instead on friends and relatives. However those who did report using brokers for financial advice reported higher saving rates, and had more assets in stocks and mutual funds. This may be because brokers are better able to explain risk and return to relatively financially uneducated people, and in particular combat loss aversion described by the psychological literature.

We believe that at retirement people face another daunting prospect, which is the process of decumulating assets in a logical and prudent manner so as to ensure a steady stream of consumption in old age. Whether people do this sensibly has received very little attention as yet. One reason is that past researchers lacked data covering this crucially important financial phase of life. However recent longitudinal data collected in the HRS and the AHEAD surveys have begun to rectify these limitations. Based on the evidence to date, we concluded that people have been able to move into retirement with ever smaller components of their wealth in bequeathable, nonannuitized, form. This is challenging retirees to manage their wealth ever more carefully, as compared to a world in which most benefits are government pensions mandatorily annuitized. We argued that there will probably be an enhanced demand for private annuities in the future as a result of the move away from annuitization by company pensions and, perhaps, by government pensions as well.

\section{Looking Ahead}

There are four developments that we believe will have a powerful effect on retirement accumulation and decumulation patterns in the future. First, it seems clear that the switch from defined benefit to defined contribution plans will continue. Sponsoring employers believe that the DC option affords them a predictable benefit offering that meets workers' needs, without the additional complexity and risk-bearing associated with DB pensions. Employees too have become accustomed to the greater portability associated with DC pensions along with the ability to invest accruing assets as they see fit. As this movement carries over to the public sector, workers everywhere will have to become more alert to the need to save more, to meet retirement accumulation targets.

A second factor likely to have an influence on retirement saving and dissaving patterns is government policy regarding tax qualified contributions to and withdrawal patterns from 
retirement accounts. Research reviewed above suggests that government tax qualification limits on pension savings as well as maximum tax deferred payouts have important effects on the amounts people put into and take out of their pensions. Any changes in government policy regarding the tax status of pension contributions or benefits could powerfully affect future retirement saving patterns.

A third factor likely to influence saving and asset allocation patterns is the recent introduction of inflation-indexed bonds or Treasury Inflation Protection Securities (TIPS). While new to the United States, they have proven rather successful in Britain amounting to some $20 \%$ of outstanding debt since their introduction more than a decade ago. Instruments of these sort have long been advocated by economists who see them both as an instrument that allows investors to hedge inflation risk and as a tool to accurately gauge market expectations of future inflation. While there are still some questions regarding the true inflation hedging ability of these instruments given current tax treatment, in certain circumstances they may prove quite beneficial.24 The most obvious of these is inclusion in tax-favored savings vehicles such as IRA's and 401(k)'s where the inflation protection would be maintained.

Once the market for this debt is deeper and a wider variety of maturities are available, we may see a veritable menu of inflation-indexed products. The introduction of TIPS should lay a foundation for other public and private entities to follow suit and issue inflation indexed debt. More importantly for our purposes, TIPS should allow for the introduction and development of a variety of products to ensure consumption in retirement. These will include strips of TIPS into interest and principal components, nominal for indexed swaps, inflation options, inflation insurance, and possibly most importantly for retiree households, indexed annuity products.

Although inflation is currently rather low by historical terms, an inflation rate of $3.5 \%$ cuts purchasing power in half in 20 years. The longer the period over which an income stream is paid out, the more important inflation protection becomes. If retirement ages do not increase as life expectancy increases, demand for indexed annuities should continue to grow as the baby boom approaches and moves into retirement.

Finally, it is crucial to remind ourselves of the central role played by social security in retirees' incomes today, and how the promise of this benefit profoundly influences today's workers as they plan for their own retirement. What is difficult to foretell is how taxes and benefits will be adapted to bring what is currently an insolvent system into balance again. If taxes are raised in accord with the proposal to maintain benefits, private saving will not increase and may even decline - which could exacerbate the saving shortfall identified above. By contrast if the system were downsized so that only a minimum guarantee were provided by the government plan and all extra 
taxes saved in individual accounts, this might raise private saving - though the overall effect would depend on whether the individual accounts would be fully offset by reductions in other saving. In any event, a massive change in the nation's major source of retirement income would be expected to have substantial spillover effects on private asset accumulation and decumulation patterns.

\section{A Shift in Focus}

It is inevitable that, in the future, American households will bear more of the burden for their consumption in retirement. As defined contribution pensions continue to replace defined benefit pension plans, and when social security is reformed, this will bring about fundamental shifts in peoples' retirement holdings. Already we have seen this, beginning among the assets held by those with $401(\mathrm{k})$ accounts. Stocks are accounting for a greater and greater percentage of the assets held. This may be a combination of a number of factors including a prolonged bull market and increasing sophistication and education of plan participants.

Clearly more work needs to be done on these fronts. Households need to be educated on the need for saving and the availability of vehicles for doing so. Why households do not make better and more frequent use of tax-favored vehicles such as IRA's remains a puzzle. If households are not accumulating enough assets for retirement under our benchmarks, it might be because households are aware of this and simply plan to significantly reduce consumption in retirement. Alternatively, if people are not aware of their sizable wealth shortfall, they will find eventually that they are forced to consume much less than anticipated, and/or turn to government programs for support in old age. Should social security benefits be cut, reductions in old age consumption will be even greater.

In the last half century the United States saw a substantial risk transfer from the individual to the group, with the development of massive government institutions such as social security and Medicare, along with employer sponsored defined benefit pension plans to protect consumption in old age. This pattern has now reversed and will continue down this track in the future, with new pension and saving vehicles transferring risk back to individuals and households. While the increased personal responsibility imposed by these changes has many positive aspects, it does raise problems regarding the almost complete elimination of some traditional risk pooling mechanisms. For instance, retirees are much more exposed to longevity risk without annuities, and to some degree they are more exposed to investment risk when they hold lump sums with no predetermined draw-down path,

\footnotetext{
${ }^{24}$ It may be argued that the British stimulated demand for inflation indexed debt by changing their tax laws so that capital gains are calculated in real terms. Moore (1995) discusses this and other issues relating to the introduction and demand for inflation-indexed debt.
} 
Evidently the change in the market for retirement accumulation and decumulation has produced substantial d\&intermediation, where people bear more risk directly instead of relying on traditional wealth-building and wealth-preserving institutions and mechanisms. In order for these changes to proceed smoothly, individuals must become more educated, and probably hold more reserves, to substitute for these displaced institutions and mechanisms. It seems likely that these changes provide an opportunity for new devices for saving, as well as methods to strengthen existing ones. One approach we have explored here involves educating workers as to their projected future needs will be, and instructing them about how to save to meet these needs. This will probably require expansion of existing programs such as IRA's and 401(k)'s by increasing contribution limits, expanding tax-qualified status, and perhaps allowing greater flexibility in borrowing from these programs to increase their apparent liquidity while maintaining an emphasis on retirement saving.

In addition, insurance and financial markets will be called on to take an expanded role in risk pooling. If households increasingly manage their own retirement assets instead of having corporate pension managers handle the funds in defined benefit pension plans, there will be a greater need for individual annuity products to hedge mortality risk. As life expectancy increases and social security provides less of a hedge against inflation risk, indexed annuities should command a greater piece of the individual annuity market.

This is a time of substantial change and opportunity in retirement planning research, as well as for financial products aimed at helping people increase their retirement security. An exciting range of new questions can now be examined with emerging datasets, testing aspects of the theoretical framework explaining retirement accumulation and decumulation. This blending of theory and empirical research promises useful answers to practical questions about why people save, what instruments they save with, and how they consume their savings in retirement questions of central importance to the future of retirement in America. 


\section{References}

Ando, Albert and Franco Modigliani, "The Life Cycle Hypothesis of Saving: Aggregate Implications and Tests," American Economic Review 53, March 1963, pp. 53-84.

Bajtelsmit, Vickie and Jack Vanderhei. "Risk Aversion in Pension Investment Choices". In Positioning Pensions for the Twentv-First Century. Eds. Michael Gordon,Olivia Mitchell, and Marc Twinney. Pension Research Council. Philadelphia: University of Pennsylvania Press, forthcoming. Bayer, Patrick J., B. Douglas Bernheim, and John Karl Scholz. "The Effects of Financial Education in the Workplace: Evidence from a Survey of Employers" NBER Working Paper 5655, July 1996.

Benartzi, Shlomo and Richard Thaler. "Risk Aversion or Myopia? The Fallacy of Small Numbers and its Implications for Retirement Savings". Unpublished paper, University of Chicago. April 1996.

Bernheim, B. Douglas. Is the Baby Boom Generation Preparing Adeauatelv for Retirement?

Technical Renort. Princeton, N. J., Merrill Lynch, 1992.

Bernheim, B. Douglas, 1993. Is the Babv Boom Generation Preparing Adeauately for

Retirement? Summarv Renort. Princeton, N. J., Merrill Lynch, 1993.

Bernheim, B. Douglas. The Merrill Lvnch Baby Boom Retirement Index. Stanford University. Merrill Lvnch, 1994.

Bernheim, B. Douglas. "Rethinking Saving Incentives," Stanford University Economics Working Paper 96-009, March 1996.

Bernheim, B. Douglas. "Financial Illiteracy, Education, and Retirement Saving," In Living

With Defmed Contribution Plans. Eds. Olivia Mitchell and Sylvester Schieber. Pension Research Council. Philadelphia: University of Pennsylvania Press, forthcoming.

Bernheim, B. Douglas and Daniel M. Garrett. "The Determinants and Consequences of Financial Education in the Workplace: Evidence from a Survey of Employers". NBER Working Paper 5667, July 1996.

Bodie, Zvi. "On the Risks of Stocks in the Long Run," Financial Analysts Journal, May-June 1995, pp. 18-22.

Bodie,Zvi, Robert Merton, and William Samuelson. "Labor Supply Flexibility and Portfolio Choice in a Life Cycle Model". Journal of Economic Dynamics and Control 16. July/Oct. 1992: 42749.

Brown, Stephen J., William N. Goetzmann, and Stephen A. Ross. "Survival," Journal of Finance 50:3, July 1995, pp. 853-873.

Browning, Martin, and Annamaria Lusardi. "Household Saving: Micro Theories and Micro

Facts," Journal of Economic Literature 34, December 1996, pp. 1797- 1855.

Canner, Niko, N. Gregory Mankiw, and David N. Weil. "An Asset Allocation Puzzle". NBER

Working Paper 4857, September 1994.

Chang, Angela. "Tax Policy, Lump Sum Pension Distributions, and Household Saving".

National Tax Journal v. 49 (2): 1995: 235-253.

Clark, Robert L. and Sylvester J. Scheiber. "Factors Affecting Participation Rates and

Contribution Levels in 401(k) Plans," In Living With Defined Contribution Plans. Eds. Olivia

Mitchell and Sylvester Schieber. Pension Research Council. Philadelphia: University of

Pennsylvania Press, forthcoming.

Cocheo, Steve. "Reverse Mortgages Shift Up a Gear," ABA Banking Journal 88: 10, October 1996, pp.77-84.

Congressional Budget Office. "Baby Boomers in Retirement: An Early Perspective. "

Washington, D.C., U.S. Government Printing Office, 1993.

Davis, Morris A, "Endogenous Mortality Risk and the Savings Behavior of the Elderly".

Unpublished Manuscript, 1996.

Deaton, Angus. Understanding Consumntion New York, Oxford University Press, 1992.

Diamond, Peter and Jerry Hausman, "Individual Savings Behavior," paper prepared for the

National Commission on Social Security, May 1980.

Disney, Richard. Can We Afford to Grow Old? Cambridge, MA: MIT Press, 1996. 
Employee Benefit Research Institute (EBRI). EBRI Databook, 3rd edition. Washington D.C.: EBRI, 1995.

Engen, Eric M., William G. Gale, and John Karl Scholz. "The Illusory Effects of Saving Incentives on Saving," Journal of Economic Perspectives 10:4, Fall 1996, pp. 113-138.

Feenberg, Daniel and Jonathan Skinner. "Sources of IRA Saving," Tax Policy and the Economy 3, 1989, pp. 25-46.

Feldstein, Martin. "Do Private Pensions Increase National Saving?” Discussion Paper 553, Harvard Institute of Economic Research, 1977.

Gale, William G. and John Karl Scholz. "IRA 's and Household Saving," American Economic Review 84:5, December 1994, pp. 1233-60.

Gokhale, Jagadeesh, Laurence J. Kotlikoff, and John Sabelhaus. "Understanding the Postwar Decline in U.S. Saving: A Cohort Analysis," Brookings Papers on Economic Activity 1:1996, pp.315-407.

Goodfellow, Gordon and Sylvester Schieber. "Investment of Assets in Self Directed Pension Portfolios," In Positioning Pensions for the Twentv-First Century. Eds. Michael Gordon,Olivia Mitchell, and Marc Twinney. Pension Research Council. Philadelphia: University of Pennsylvania Press, forthcoming.

Greenwich Associates. Onward and Unward! Greenwich Reports: Greenwich CT, 1993.

Gustman, Alan S. and F. Thomas Juster. "Income and Wealth of Older American

Households: Modeling Issues for Public Policy Analysis," In Assessing Knowledge of Retirement

Behavior. Eds. Eric Hanushek and Nancy Maritato. National Research Council. Whashington, D.C.: National Academy Press, 1996.

Gustman, Alan S., Olivia S. Mitchell, Andrew Samwick and Thomas Steinmeier. "Pension and Social Security Wealth in the Health and Retirement Study". NBER Working Paper, February 1997.

Greenwich Associates, Big Job Gets Bigger. Greenwich Investment Mangement Report: Greenwich Ct. 1993.

Hallman. G. Victor and Jerry S. Rosenbloom. Personal Financial Planning, 5e. New York: McGraw Hill, 1993.

Hinz, Richard P. and John A. Turner. "Gender Differences in Participant Directed Pension

Portfolios," In Positioning Pensions for the Twenty-First Century. Eds. Michael Gordon,Olivia Mitchell, and Marc Twinney. Pension Research Council. Philadelphia: University of Pennsylvania Press, forthcoming.

Hubbard, R. Glenn and Jonathan Skinner. "Assessing the Effectiveness of Saving Incentives," Journal of Economic Perspectives 10:4, Fall 1996, pp. 73-90.

Hubbard, R. Glenn, Jonathan Skinner, and Stephen P. Zeldes. "The importance of precautionary motives in explaining individual and aggregate saving," Carnegie-Rochester Conference Series on Public Policy 40, 1994, pp.59-125.

Hubbard, R. Glenn, Jonathan Skinner, and Stephen P. Zeldes. "Social Insurance and Precautionary Saving," Journal of Political Economy 103:2, April 1995, pp.360-99.

Hurd, Michael D. "The Adequacy of Retirement Resources and the Role of Pensions". SUNY Stony Brook, Working Paper October 1993.

Hammond, Brett. "The Importance of Variable Annuities". In Living With Defined

Contribution Plans. Eds. Olivia Mitchell and Sylvester Schieber. Pension Research Council.

Philadelphia: University of Pennsylvania Press, forthcoming.

Hurd, Michael D. and Kathleen McGarry. "Evaluation of the Subjective Probabilities of Survival in the Health and Retirement Study," Journal of Human Resources 30, Supplement 1995, pp. S268-S292.

Jagannathan, Ravi, and Narayana Kocherlakota, "Why Should Older People Invest Less in Stocks Than Younger People?", Federal Reserve Bank of Minneapolis Quarterly Review, Summer 1996: 1 1-23.

Kennickell, Arthur, Martha Starr McCluer, and Annika Sunden. "Financial Advice and Household Portfolios”. Unpublished paper, Federal Reserve Board, September 1996. 
Kotlikoff, Laurence J. and Avia Spivak. "The Family as an Incomplete Annuities Market". Journal of Political Economy 89 (2, April 1981): 372-391.

Kusko, Andrea L., James M. Poterba, and David W. Wilcox. "Employee Decisions with Respect to 401(k) Plans: Evidence From Individual-Level Data," In Living With Defmed Contribution Plans. Eds. Olivia Mitchell and Sylvester Schieber. Pension Research Council. Philadelphia: University of Pennsylvania Press, forthcoming.

Lee, Ronald, and Jonathan Skinner. "Assessing forecasts of mortality, health status, and health care costs during baby boomers' retirement." In Modeling the Impact of Public and Private Policies on Retirement Behavior and Income, C. Citro, ed. National Academy of Science, Washington, 1996.

Levine, Phillip and Olivia S. Mitchell. "Women on the Verge of Retirement" Pension Research Council Working Paper January 1997.

Malkiel, Burton. A Random Walk Down Wall Street New York: W.W. Norton, 1995.

McGill, Dan M., Kyle N. Brown, John J. Haley, and Sylvester J. Schieber. Fundamentals of Private Pensions , 7th edition. Philadelphia: University of Pennsylvania Press, 1996.

Mitchell, Olivia, Jan Olson, Thomas Steinmeier. "Construction of the Earnings and Benefits

File (EBF) for Use with the Health \& Retirement Study," NBER Working Paper 5707, 1996.

Mitchell, Olivia S., James Poterba, and Mark Warshawksy. "New Evidence on the Money's

Worth of Individual Annuities". NBER Working Paper 6002. April 1997.

Modigliani, Franco and Richard Brumberg. "Utility Analysis and the Consumption

Function: An Interpretation of Cross-section Data," in Kenneth K. Kurihara, ed., Post-Keynesian

Economics, Rutgers University Press, New Brunswick, NJ, 1954.

Moore, James F. "Should the United States Issue Granny Bonds? An Exploration of the

Demand for Index-Linked Debt," Manuscript, December 1995.

Moore, James F. and Olivia S. Mitchell. "Projected Wealth and Implications for Retirement

Saving in the Health and Retirement Study," Manuscript, February 1997.

Munnell, Alicia H. The Economics of Private Pensions Brookings Studies in Social

Economics, The Brookings Institution, Washington, D.C., 1982.

Nixon, Brian. "Moving Forward with Reverse Mortgages," America's Community Banker

5:5, May 1996, pp. 24-28.

Palmer, Bruce A. "The Impact of Tax Reform on Wage Replacement Ratios," Georgia State

University, Center for Risk Management and Insurance Research, 1988.

Palmer, Bruce A. "1991 Georgia State University/Alexander \& Alexander Consulting Group RETIRE Report," Georgia State University, Center for Risk Management and Insurance Research, 1991.

Palmer, Bruce A. "1993 Georgia State University/Alexander \& Alexander Consulting Group RETIRE Report," Georgia State University, Center for Risk Management and Insurance Research, 1993.

Poterba, James M., Steven F. Venti, and David A. Wise. "Do 401(k) Contributions Crowd

Out Personal Saving?" NBER Working Paper 4391, June 1993.

Poterba, James M., Steven F. Venti, and David A. Wise. "Personal Retirement Saving Programs and Asset Accumulation: Reconciling the Evidence" NBER Working Paper 5599, May 1996. [ 1996a]

Poterba, James M. and David A. Wise. "Individual Financial Decisions in Retirement Saving Plans and the Provision of Resources for Retirement". NBER Working Paper 5672, September 1996. [1996b]

Poterba, James M., Steven F. Venti, and David A. Wise. "How Retirement Saving Programs Increase Saving," Journal of Economic Perspectives 10:4, Fall 1996, pp. 91-112. [1996c]

Rasmussen, David W., Issac F. Megbolugbe, and Barbara A. Morgan. "Using the 1990 Public Use Microdata Sample to Estimate Potential Demand for Reverse Mortgage Products," Journal of Housing Research 6: 1, 1995, pp. 1-23.

Samuelson, Paul A., "The Long-Term Case for Equities and How It Can Be Oversold," Journal of Portfolio Management, Fall 1994, pp. 15-24. 
Schieber, Sylvester and John B. Shoven. "The Consequences of Population Aging on Private Pension Fund Saving and Asset Markets”. NBER WP 4665. March 1994.

Siegel, Jeremy J. Stocks for the Long Run. Chicago: Irwin, 1994.

Shefrin, Hersh M. and Richard H. Thaler. "The Behavioral Life-Cycle Hypothesis," Economic Inauiry 26, October 1988, pp. 609-43.

Skinner, Jonathan. "Housing and Saving in the United States". In Housing Markets in the United States and Japan. Eds. Y. Noguchi and J. Poterba. Chicago: University of Chicago Press, 1994.

Smith, James. "Racial and Ethnic Differences in Wealth in the Health and Retirement Study," Journal of Human Resources 30, Supplement 1995, pp. S158-S183.

Technical Panel on Trends in Income and Retirement Savings (TIRS), Final Renort to the Social Security Advisorv Council, US Department of Health and Human Services, December 1995. (Also available via internet at www.ssa.gov).

Thaler, Richard H. "Psychology and Savings Policy", American Economic Review 84:2, May 1994, pp. 186-92.

US Department of Labor. Private Pension Plan Bulletin: Abstract of 1993 Form 5500 Annual Reports. PWBA no. 6, Winter 1997.

Venti, Steven F. and David Wise. "Aging and the Income Value of Housing Wealth". Journal of Public Economics 1991 v 44(3): 371-398.

Weil, David N. "The Saving of the Elderly in Micro and Macro Data," Quarterly Journal of Economics, 1994, pp. 55-81.

Williams, Fred. "Equities top 62\% of 401(k) Assets". Pensions and Investments, 1/20/97: 1. 
Table I.A.l: Wealth Components by Source in the HRS Around the Time of Retirement (\$1992)

\begin{tabular}{|c|c|c|c|c|c|c|}
\hline \multirow[b]{3}{*}{ Source of Wealth } & \multirow{2}{*}{\multicolumn{2}{|c|}{ Mean for Sample }} & \multicolumn{2}{|c|}{ Median 10\% of Household! } & \multirow{2}{*}{\multicolumn{2}{|c|}{$\begin{array}{c}\text { Among Households Holding } \\
\text { Wealth Sources }\end{array}$}} \\
\hline & & & \multirow[b]{2}{*}{$\begin{array}{l}\text { Dollar } \\
\text { Value }\end{array}$} & & & \\
\hline & $\begin{array}{l}\text { Dollar } \\
\text { Value }\end{array}$ & $\begin{array}{l}\text { Percent of } \\
\text { Total }\end{array}$ & & \multirow{2}{*}{ 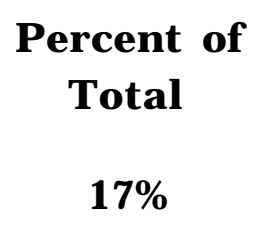 } & $\begin{array}{c}\text { Average Value } \\
\text { Among } \\
\text { Source Holders }\end{array}$ & $\begin{array}{l}\text { Percent of } \\
\text { Sample with } \\
\text { S ou c e }\end{array}$ \\
\hline (1) Net Financial Wealth & $\$ 163,087$ & $32 \%$ & $\$ \quad \mathbf{5 9 , 3 3 5}$ & & & \\
\hline Business Assets & 78,951 & 16 & 14,511 & 4 & 250,198 & $32 \%$ \\
\hline Financial Assets & 42,140 & 8 & 19,274 & 6 & 47,709 & 188 \\
\hline Individual Retirement Holdings & 19,613 & 4 & 10,948 & 3 & 46,716 & 42 \\
\hline Other & 22,383 & 4 & 14,602 & 4 & & \\
\hline (2) Net Home Value & 78,826 & 16 & 67,716 & 20 & 98,456 & 80 \\
\hline (3) Retirement Wealth & 257,274 & 52 & 212,674 & 63 & & \\
\hline Social Security Wealth & 133,662 & 27 & 144,801 & 43 & 138,878 & 96 \\
\hline Pension Wealth & 116,012 & 23 & 60,102 & 18 & 181,926 & 64 \\
\hline Retiree Health Insurance & 7,600 & 2 & 7,771 & 2 & 23,841 & 32 \\
\hline (4) Total Wealth & 499,187 & 100 & 339,725 & 100 & & \\
\hline Number of Observations & 7,607 & & & & & \\
\hline
\end{tabular}


Table I.A.2: Distribution of Wealth Components in the HRS Around the Time of Retirement (\$1992)

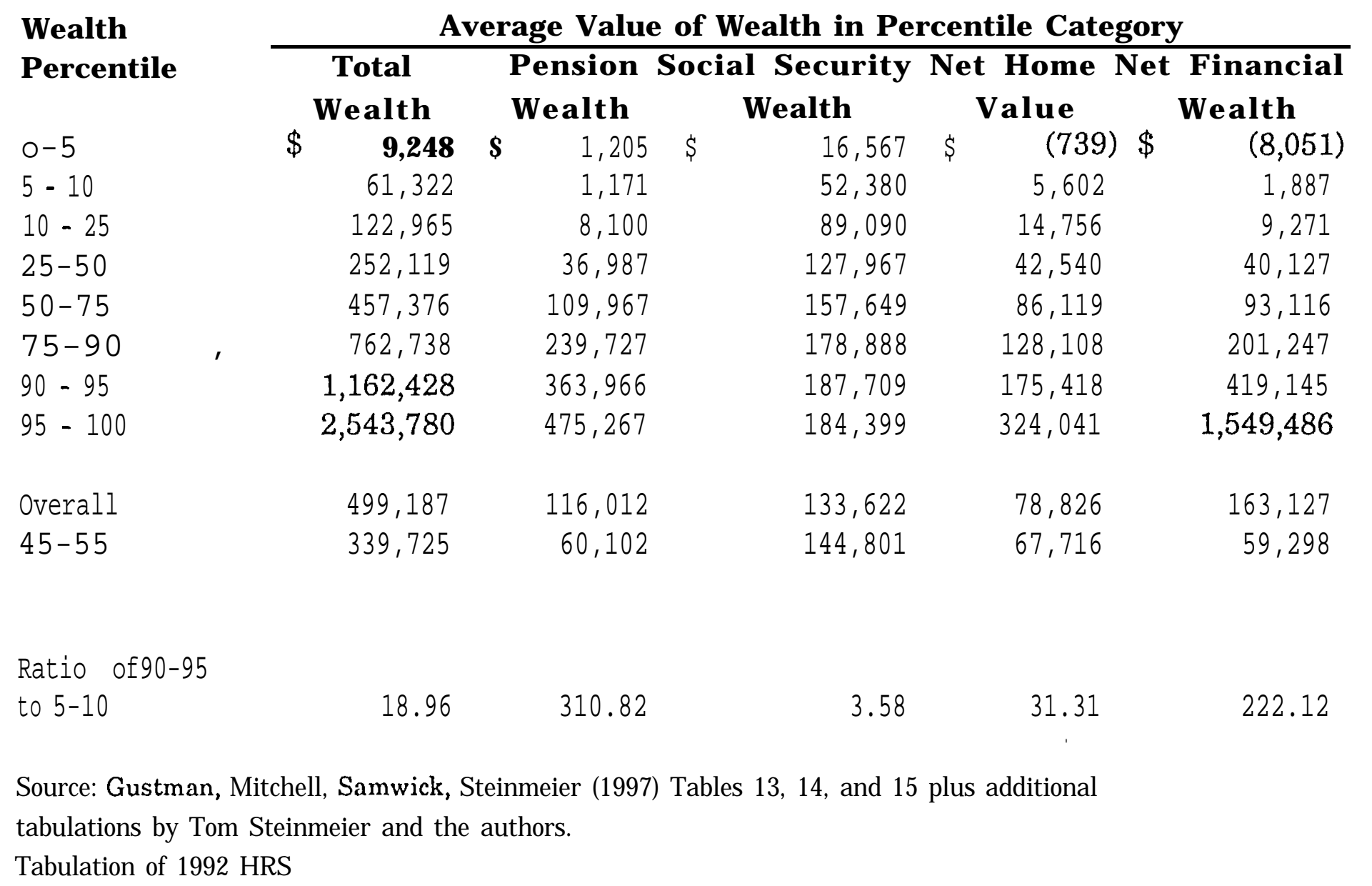


Figure I.A.l: Distribution of Wealth Components in the HRS Around the Time of Retirement

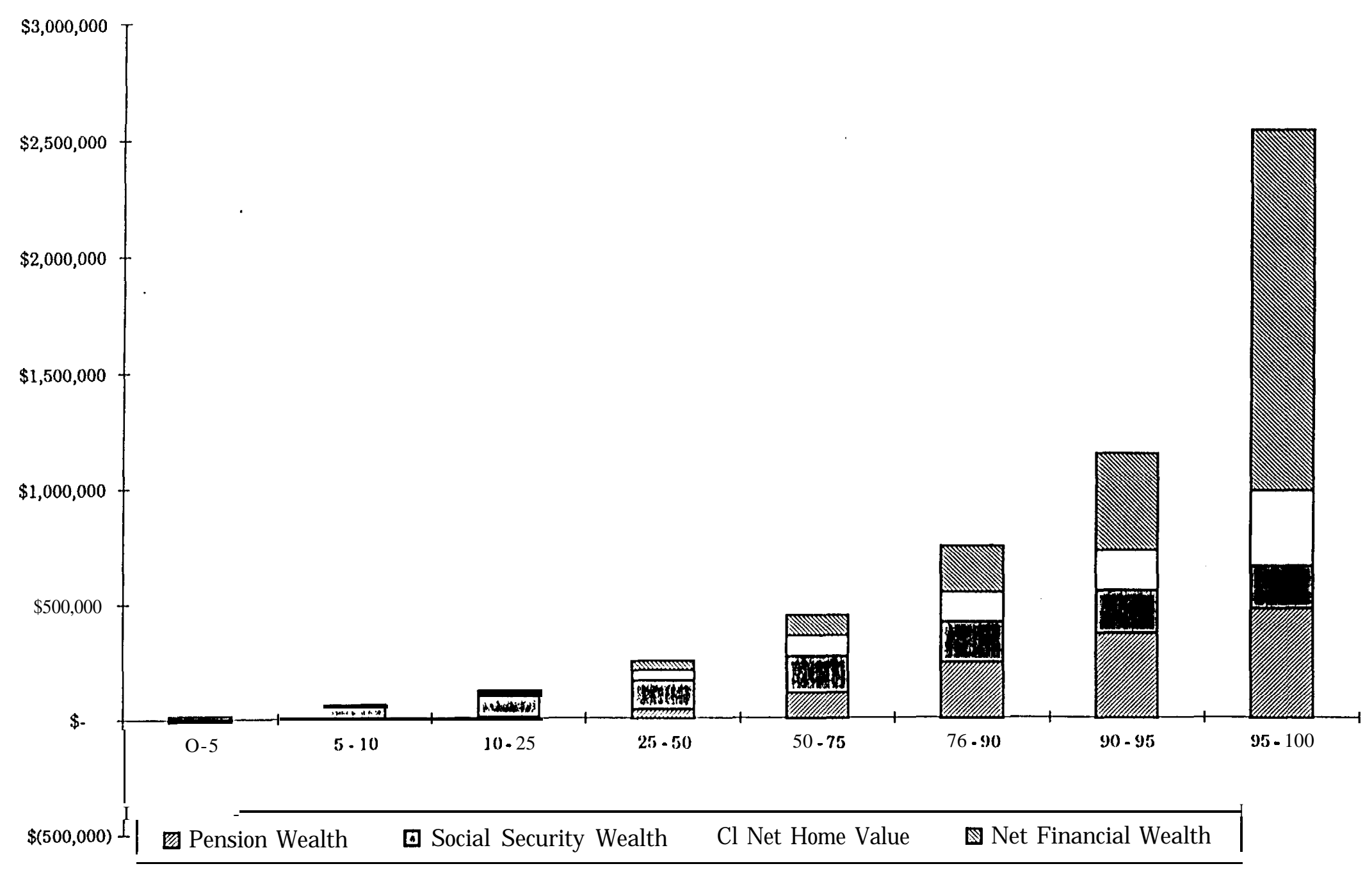


Table I.A.3: Net Financial Wealth in the HRS Around the Time of Retirement

By Household Characteristics (\$1992)

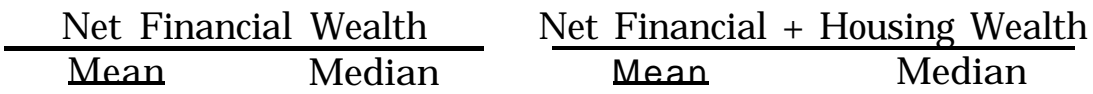

\section{Education \\ Less Than High School \\ High School Degree \\ College Degree \\ Advanced Degree}

Marital Status

Married Couple

Single Male

Single Female

Race

Black

Hispanic
White

$\begin{array}{rrr}\$ 132,180 & \$ & 18,000 \\ 141,831 & & 40,000 \\ 291,441 & & 101,000 \\ 373,752 & & 139,000\end{array}$

220,539

144,980

60,953

201,780
53,300
66,525

Household Income Quintile

$$
\begin{aligned}
& 0-20 \% \\
& 20-40 \% \\
& 40-60 \% \\
& 60-80 \% \\
& 80-100 \%
\end{aligned}
$$

55,982
88,585
115,569
173,095
446,778

175,974

7,607
64,000

21,000

8,000

56,000

5,000

5,000

3,000

17,650

41,000

68,220

165,200

41,150

241,913

84,873

135,658

179,852

247,686

561,669
126,700

28,500

31,500

139,100

45,000

36,904

18,000

58,850

102,250

140,000

276,000

102,000

Number of Households 
Table I.A.4: Trends in Net Financial Weath Including Housing - Baby Boomers versus Their Parents (\$1992)

\begin{tabular}{|c|c|c|c|c|c|c|}
\hline & \multicolumn{3}{|c|}{ First Wave* } & \multicolumn{3}{|c|}{ Second Wave* } \\
\hline & $\begin{array}{c}\text { Boomers' } \\
\text { Financial } \\
\text { Wealth }\end{array}$ & $\begin{array}{c}\text { Parents' } \\
\text { Financial } \\
\text { Wealth }\end{array}$ & $\underline{\text { Ratio }}$ & $\begin{array}{c}\text { Boomers' } \\
\text { Financial } \\
\text { Wealth }\end{array}$ & $\begin{array}{c}\text { Parents' } \\
\text { Financial } \\
\text { Wealth }\end{array}$ & $\underline{\text { Ratio }}$ \\
\hline \multicolumn{7}{|c|}{ Household Income Quintile } \\
\hline $0-20 \%$ & 200 & 300 & 0.67 & 1,100 & $\$ 2,100$ & 0.52 \\
\hline $20-40 \%$ & 3,300 & 2,700 & 1.22 & 25,300 & 12,700 & 1.99 \\
\hline $40-60 \%$ & 12,000 & 8,000 & 1.50 & 70,700 & 34,300 & 2.06 \\
\hline $60-80 \%$ & 18,200 & 19,100 & 0.95 & 76,800 & 63,300 & 1.21 \\
\hline $80-100 \%$ & 80,800 & 28,000 & 2.89 & 184,000 & 89,000 & 2.07 \\
\hline Sample Medians & 9,900 & 6,700 & 1.48 & $\mathbf{5 9 , 5 0 0}$ & 32,200 & 1.85 \\
\hline
\end{tabular}

Note: *First Wave baby boomers are defined as the cohort born 1946 - 55 (age 35 - 44 in 1989); Second Wave baby boomers are the cohort born 1956 - 64 (age 25 - 34 in 1989). Parents' cohorts are those of the same age groupings in 1962. All dollar figures are in 1992 dollars.

Source: Congressional Budget Office 1993 tabulation of 1962 and 1989 Survey of Consumer Finance. 


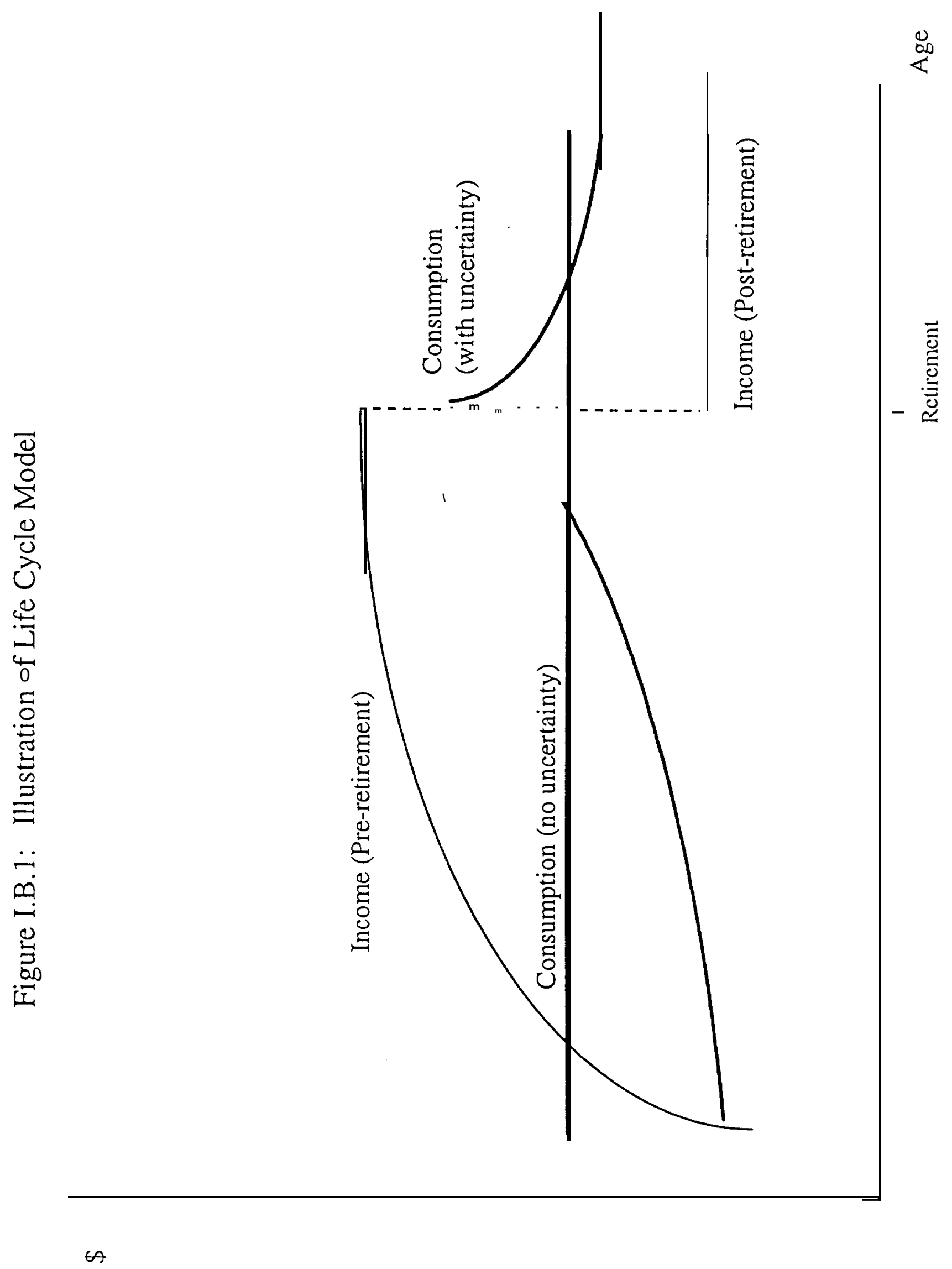


Figure I.B.2 : Recommended Replacement Rates

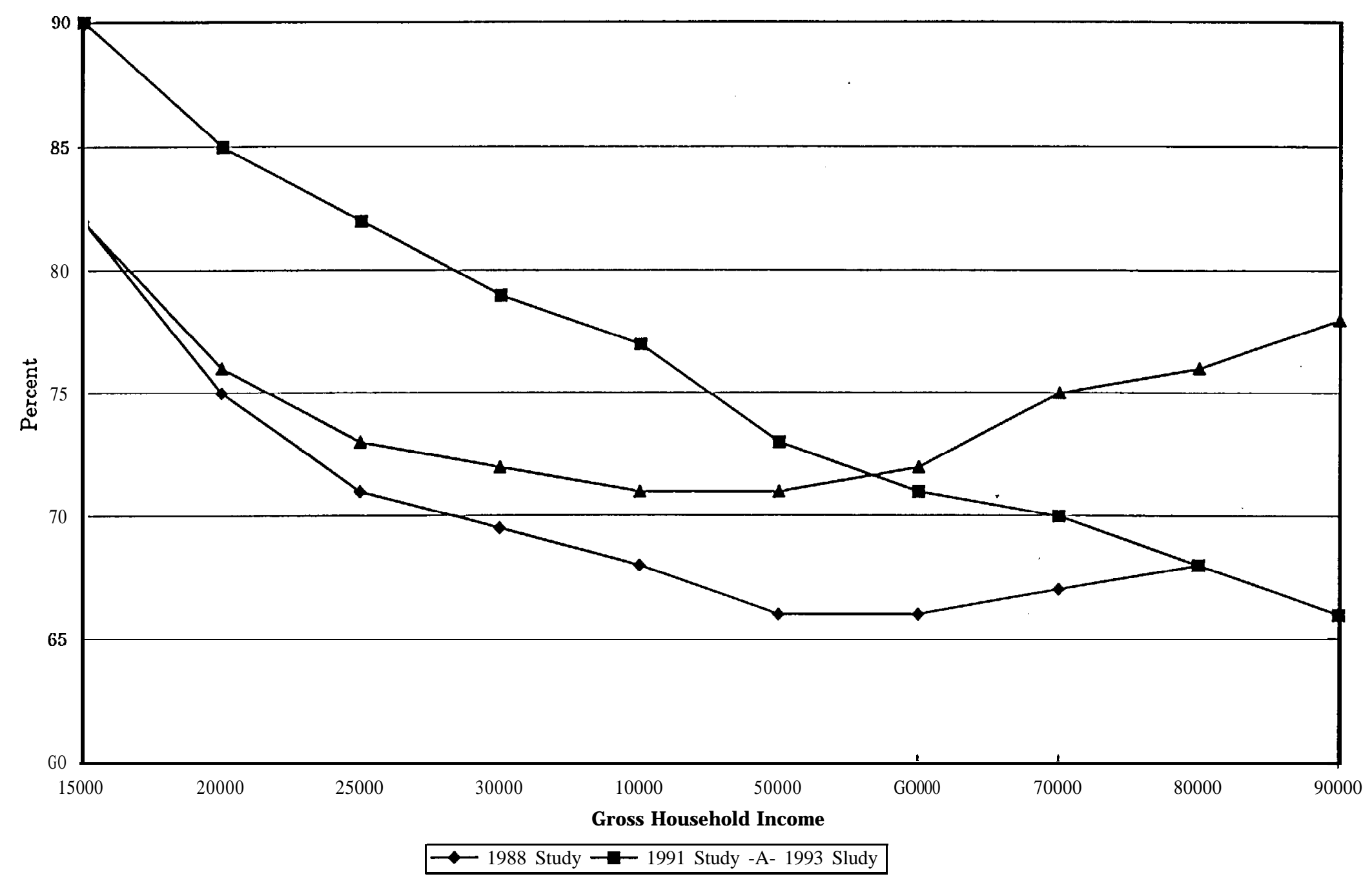


Figure I.B.3: Schematic Diagram of Dynamic Programming Approach to Life Cycle with Uncertainty

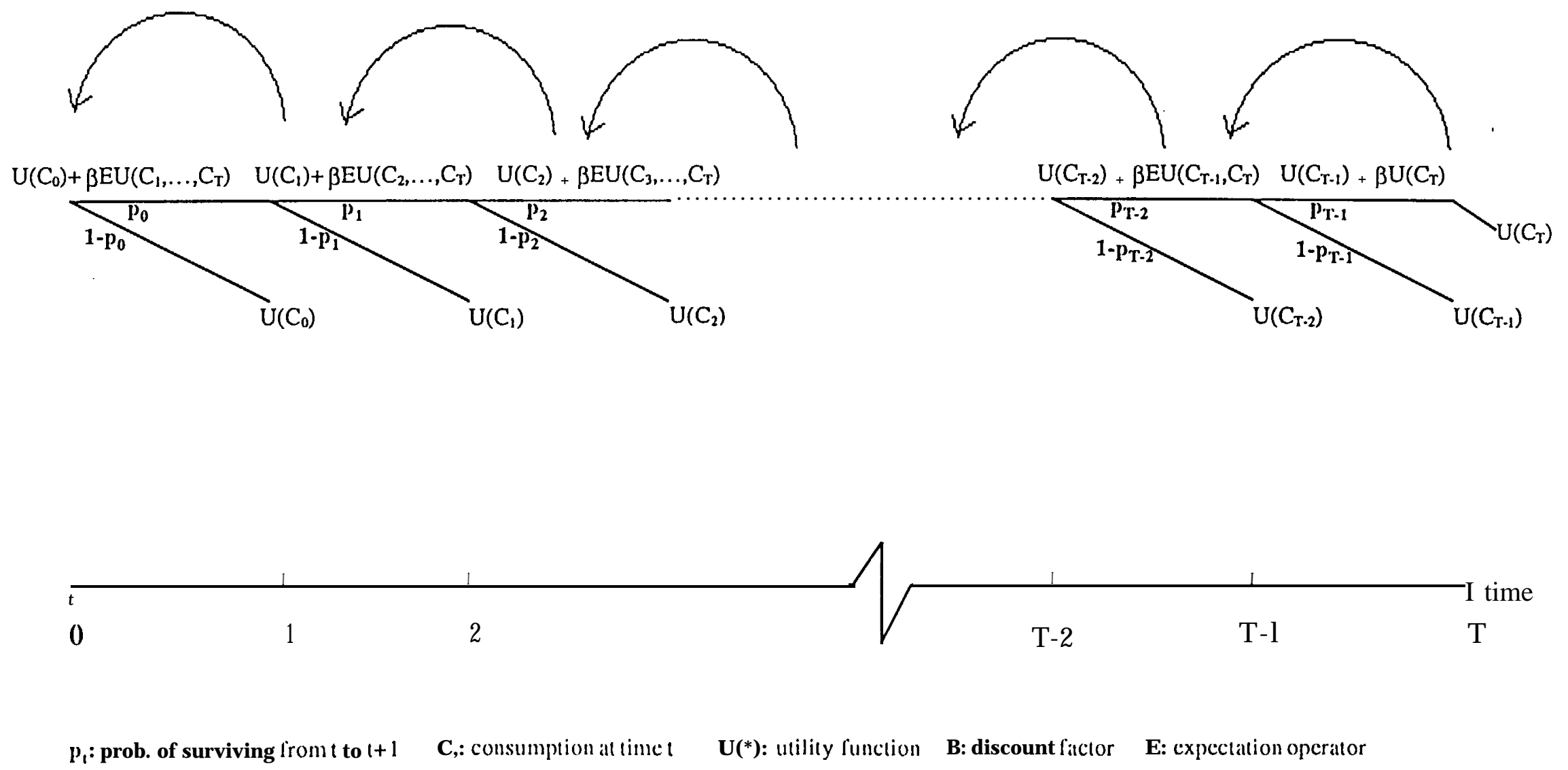


Table I.B.1.: Projection of HRS Household's Current Assets to Age 65 (\$1992)

\section{Net Financial Wealth}

$\begin{array}{lrr}\text { Current (Age 56) } & \text { \$ 59,300 } \\ & \text { Assumed } & \\ \text { Projected Growth } & \text { Return (real) } & \\ 40 \% \text { Stocks } & 9.2 \% & 28,700 \\ 60 \% \text { Govt. Bonds } & 2.5 \% & \mathbf{8 , 9 0 0} \\ \text { Projected at age 65 } & & \mathbf{9 6 , 9 0 0}\end{array}$

\section{Net Home Value}

Current (Age 56)

$.67,700$

Projected Increase in

Value to age 65

10,300

Projected at age 65

78,000

Pension Wealth

Current (Age 56)

60,100

Expected Asset Growth

34,800

and Accruals

Projected at age 65

$\mathbf{9 4 , 9 0 0}$

Social Securitv Wealth

Current (Age 56)

148,200

Projected Increase

27,300

Proj. at age 65

175,500

Projected Total Value of

Current Assets at 65

445,300 
Table I.B.2.: Projection of Saving Rates needed to Meet Replacement Rates

\begin{tabular}{lll}
\multicolumn{3}{c}{ Real Discount Rate } \\
\hline $\mathbf{1 . 0} \%$ & $2.5 \%$ & $4.0 \%$
\end{tabular}

$80 \%$ Replacement Ratio

\section{$100 \%$ J\&S}

-Amt Needed to Sustain

-Shortfall

-Annual Saving to meet goal

- as a percentage of income

\section{0\% J\&S}

-Amt Needed to Sustain

-Shortfall

-Annual Saving to meet goal

- as a percentage of income

$\begin{array}{rrr}\$ 768,300 & \$ 645,600 & \$ 551,400 \\ 323,000 & 200,300 & 106,100 \\ 28,800 & 17,800 & 9,500 \\ 62.6 \% & 38.7 \% & 20.7 \%\end{array}$

$\$ 599,800$

154,500

$\$ 514,800$

$\$ 448,300$

69,500

3,000

13,800

6,200

300

$30.0 \%$

$13.5 \%$

$0.7 \%$

70\% Replacement Ratio

\section{$100 \% \mathrm{~J} \& \mathrm{~S}$}

-Amt Needed to Sustain

-Shortfall

-Annual Saving to meet goal

- as a percentage of income

\section{$50 \% \mathrm{~J} \& \mathbf{S}$}

-Amt Needed to Sustain

-Shortfall.

-Annual Saving to meet goal

- as a percentage of income

$\begin{array}{rrr}\$ 672,300 & \$ 564,900 & \$ 482,400 \\ 227,000 & 119,600 & 37,100 \\ 20,200 & 10,700 & 3,300 \\ 43.9 \% & 23.3 \% & 7.2 \%\end{array}$

$\begin{array}{rrr}\$ 524,800 & \$ 450,500 & \$ 392,300 \\ 79,500 & 5,200 & 0 \\ 7,100 & 500 & 0 \\ 15.4 \% & \mathbf{1 . 1 \%} & \mathbf{0 . 0 \%}\end{array}$


Table I.B.3: Current and Projected Retiree Well-Being in the HRS by Race, Marital Status, \& Sex

$$
\text { White Black }
$$

\section{Well Being by Race and Sex}

MEASURES BASED ON CURRENT INCOME

Median income-to-needs ratio

$\%$ in poverty

MEASURES BASED ON

PROJECTED RETIREMENT INCOME

Projected median income-to-needs ratio including housing wealth

Projected median income-to-needs ratio excluding housing wealth

Projected \% in poverty

Projected \% in poverty, excluding housing wealth

II. Well Being by Marital Status and Sex

MEASURES BASED ON CURRENT INCOME

Median income-to-needs ratio

$\%$ in poverty

MEASURES BASED ON

PROJECTED RETIREMENT INCOME

Projected median income-to-needs ratio including housing wealth

Projected median income-to-needs ratio excluding housing wealth

Projected \% in poverty

Projected \% in poverty, excluding housing wealth
(1)

MEN W \& $\mathrm{N}$

(3)

MEN WOMEN

$\begin{array}{llll}4.6 & 4.0 & 2.7 & 2.1 \\ 4.3 & 6.9 & 16.9 & 22.7\end{array}$

3.5

3.3

1.8

1.4

2.6

2.4

1.6

1.3

4.0

8.3

22.9

35.4

5.8

10.2

25.3

38.2

Nonmarried
(1)
(2)
MEN
WOMEN
(3)
(4)
MEN
WOMEN

$\begin{array}{cccc}4.4 & 4.2 & 2.7 & 2.1 \\ 4.1 & 5.0 & 17.8 & 22.5\end{array}$

3.1

3.3

1.8

1.1

2.4

2.4

1.4

0.9

3.9

4.4

22.3

34.9

4.9

5.3

28.2

39.6

Source: Levine and Mitchell (1995) T. 1 \& 2

Health and Retirement Survey, 1992; estimates are weighted to provide nationally representative statistics. 


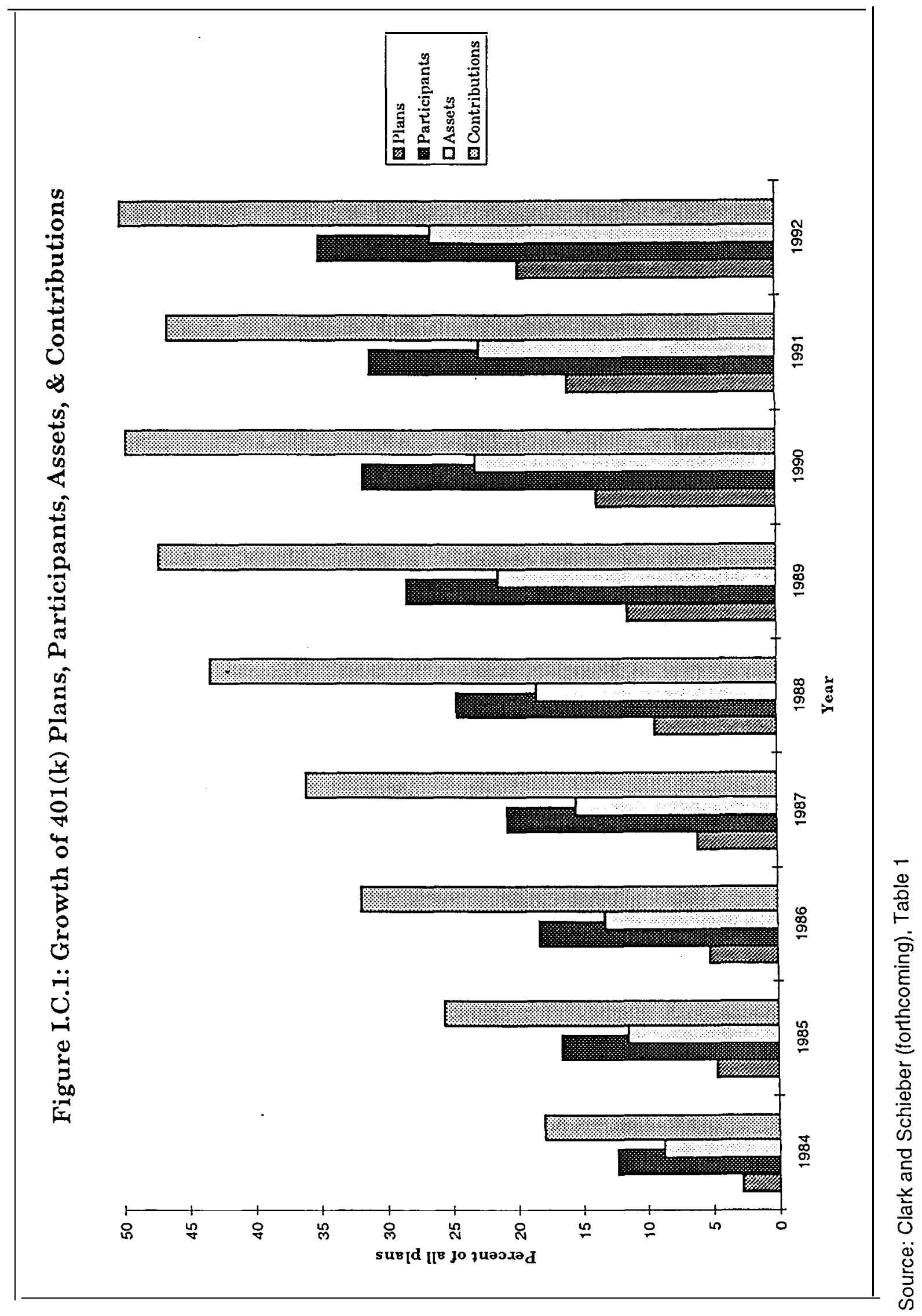


Table I.C.1.: The Effects of Frequent Retirement Seminars in the Workplace

\begin{tabular}{lccr}
$\begin{array}{l}\text { Incremental impact of } \\
\text { frequent seminars on: }\end{array}$ & $\begin{array}{c}\text { All } \\
\text { Employees }\end{array}$ & $\begin{array}{c}\text { Non-Highly } \\
\text { Compensated }\end{array}$ & $\begin{array}{c}\text { Highly } \\
\text { Compensated }\end{array}$ \\
\hline Participation Rates (\%) & $\mathbf{7 . 7 *}$ & $\mathbf{1 2 . 1 *}$ & $\mathbf{6 . 6}$ \\
Contribution Rates (\%) & $\mathbf{0 . 4}$ & $1.1 * *$ & -0.1 \\
\hline
\end{tabular}

Source: Bernheim (forthcoming)

Notes:* denotes statistical significance at the $90 \%$ level.

** denotes significance at the $95 \%$ level. 
Figure I.C.2. : Estimated Employee Contribution Rates to 401(k) Plans under Alternative Communications and Matching Programs

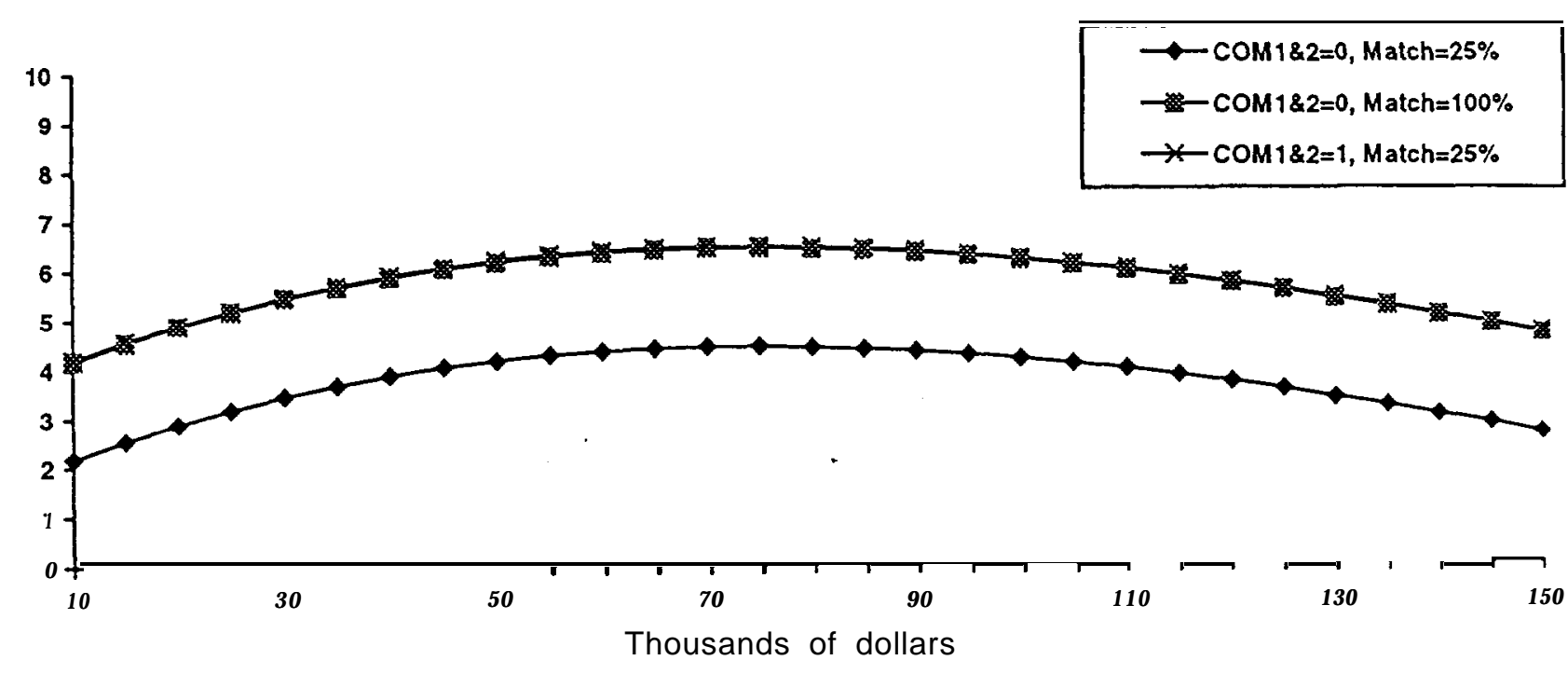

Source: Clark and Scheiber (forthcoming) 
Table II.A1: Financial Advisors' Recommended Investment Portfolio Mix

\begin{tabular}{lcccc} 
Source & \multicolumn{3}{c}{ Fraction of Portfolio } & Bonds/Stocks \\
& Stocks & Bonds & Cash/MM & $\%$ \\
\hline Conservative Investor & & & & \\
Fidelity & 20 & 30 & 50 & 1.50 \\
Merrill Lynch & 45 & 35 & 20 & 0.78 \\
Jane Bryant Quinn & 20 & 30 & 50 & 1.50 \\
New York Times & 40 & 40 & 20 & 1.00 \\
Average & 31 & 34 & 35 & 1.20 \\
Moderate Investor & & & & \\
Fidelity & 40 & 40 & 20 & 1.00 \\
Merrill Lynch & 55 & 40 & 5 & 0.73 \\
Jane Bryant Quinn & 50 & 40 & 10 & 0.80 \\
New York Times & 60 & 30 & 10 & 0.70 \\
Average & 51 & 38 & 11 & \\
& & & & 0.46 \\
Aggressive Investor & & & & 0.27 \\
Fidelity & 65 & 30 & 5 & 0.00 \\
Merrill Lynch & 75 & 20 & 5 & 0.25 \\
Jane Bryant Quinn & 100 & 0 & 0 & \\
New York Times & 80 & 20 & 0 & \\
Average & 80 & 18 & 3 & \\
& & &
\end{tabular}

Source: Derived from Canner, Mankiw, and Weil (1994):T1. 
Table II.B.l: Median Non-Housing Net Financial Assets in the HRS by Income Quintile ( $\$ 1992$ )

\begin{tabular}{lcc} 
Income Quintile & $\begin{array}{l}\text { Net Financial } \\
\text { Nonhousing Wealth }\end{array}$ & $\begin{array}{l}\text { IRA and } \\
\text { Keogh Assets }\end{array}$ \\
\hline $0-20$ & $\$ 3,000$ & $\$ 0$ \\
$20-40$ & 17,650 & 0 \\
$40-60$ & 41,000 & 0 \\
$60-80$ & 68,220 & 2,000 \\
$80-100$ & 165,200 & 15,000
\end{tabular}

Source: Authors'computations, 1992 HRS 
Table II.B.2 Pension Plan Investment Portfolios by Plan Type

Pension Fund Assets by Asset Type

as a Fraction of Net Assets

I. Private Defined Benefit

Trusteed Single Employer

Greenwich DB Universe

P\&I Top 1000 DB Plans

$$
\text { " }
$$

L arge (>100Ees)

IT. Private Defined Contribution

Trusteed Single Employer

Greenwich DC Universe

Greenwich 401(k) Universe

P\&I Top 1000 DC Plans

Large (>100Ees)

III. Private Multiemployer

Trusteed

$1993 \quad 39 \%$

$1992 \quad 44 \%$

$44 \%$

$54 \%$

$\begin{array}{ccc}1983 & 45 \% & 27 \% \\ 1993 & 42 \% & 27 \% \\ 1992 & 57 \% & 30 \% \\ 1992 & 53 \% & \text { na } \\ 1995 & 56 \% & 34 \% \\ 1996 & 57 \% & 33 \%\end{array}$

$1993 \quad 46 \% \quad 38 \%$

$1993 \quad 45 \%$

$1992 \quad 50 \%$

$1992 \quad 47 \%$

$1992 \quad 48 \%$

$1995 \quad 52 \%$

$1996 \quad 60 \%$

$1993 \quad 45 \%$

$22 \%$

$23 \%$

$40 \%$

$43 \%$

na

$33 \%$

$30 \%$

$33 \%$

$1992 \quad 33 \%$

V. Public Defined Contribution

Greenwich DC Universe

$54 \%$

\section{Other $^{(+)} \quad$ Source}

$1983 \quad 39 \%$

na

na

$9 \%$

$9 \%$

$19 \%$

$21 \%$

$5 \%$

$4 \%$

$4 \%$

EBRI T.6.10

Greenwich ‘93 p.32

Williams ('97) $1 / 29 / 97$

$"$

personal communication, PWBA, 3/97

$\begin{array}{llll}\text { na } & 15 \% & 24 \% & \text { EBRI T.6.10 } \\ \text { na } & 13 \% & 19 \% & \text { EBRI T.6.10 } \\ 0 \% & 8 \% & 3 \% & \text { Greenwich '93 p.32 } \\ 7 \% & 2 \% & 8 \% & \text { Greenwich '93 p.33 } \\ & & & \text { Williams ('97) } 1 / 29 / 97 \\ & & & \text { " } \\ \text { na } & 8 \% & 14 \% & \text { personal communication, PWBA, 3/97 }\end{array}$

$8 \%$
$16 \%$

na

$6 \%$

$5 \%$

$8 \%$

Greenwich ‘93 p.40
$5 \%$

$9 \%$

Greenwich '93 p.40

Notes:

(*) Includes GIC's and Insured funds.

(+) Totals may not sum to $100 \%$ due to rounding. 
Table II.B.3. 401(k) Assets In Specified Investment Holdings by Participant Age and Income

\begin{tabular}{lcccccc} 
& \multicolumn{7}{c}{ Plan Participant Age } & & \\
Investment Catepory & 21.30 & $\mathbf{3 1 - 4 0}$ & $\mathbf{4 1}-50$ & $\mathbf{5 1 - 6 0}$ & $\mathbf{> 6 0}$ & Total \\
\hline Stock Fund & $39 \%$ & $36 \%$ & $30 \%$ & $22 \%$ & $10 \%$ & $25 \%$ \\
Company Stock & 11 & 9 & 6 & 6 & 3 & 6 \\
International Stock & 3 & 3 & 4 & 3 & 1 & 3 \\
Balanced & 6 & 8 & 11 & 8 & 1 & 8 \\
Fixed Income & 41 & 43 & 49 & 62 & 85 & 58
\end{tabular}

Plan Participant Earnings ( $\$ \mathrm{~K})$

\begin{tabular}{|c|c|c|c|c|c|c|c|c|}
\hline Investment Category & $<15$ & $15-25$ & $25-35$ & $35-45$ & $45-60$ & $60-75$ & $75-100$ & Total \\
\hline Stock Fund & $25 \%$ & $22 \%$ & $20 \%$ & $19 \%$ & $25 \%$ & $42 \%$ & $45 \%$ & $52 \%$ \\
\hline Company Stock & 7 & 8 & 8 & 7 & 7 & 11 & 8 & 2 \\
\hline International Stock & 1 & 1 & 2 & 2 & 2 & 4 & 6 & 10 \\
\hline Balanced & 62 & 63 & 62 & 67 & 53 & 32 & 26 & 27 \\
\hline Fixed Income & 6 & 7 & 9 & 7 & 12 & 11 & 15 & 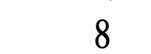 \\
\hline
\end{tabular}

Source: Goodfellowand Schieber (forthcoming) cited in Poterba and Wise (1996) 
Table II.B.4: 401(k) Assets In Specified Investment Holdings by Participant Sex, 1993

Investment Category

Allocation
Past Accumulation

Men

$14 \%$

41

45 Women $13 \%$ 42

45
New Contribution Men Women

Employer Stock

Fixed Income
$42 \%$

19

39
$44 \%$

17

40

Source: Bajtelsmit and Vanderhei (forthcoming) Table 3. 
Table II.B.5.: Asset Allocation Patterns by Sex:

Federal Thrift Savings Plan Results, 1994

Description

Percent of Employees

Government Securities Fund [G]*

StockFund [Cl alone

Bond Fund [F] alone

Stock Fund or Bond Fund

Fraction of Fund held in:

G Fund
C Fund
F Fund

G Fund

F Fund
Women $\quad \underline{\text { Men }}$

$\begin{array}{cc}100 \% & 100 \% \\ 28 & 45 \\ 12 & 20 \\ 33 & 48\end{array}$

$\begin{array}{cc}89 \% & 81 \% \\ 9 & 15 \\ 3 & 8\end{array}$

Source: Adapted from Hinz and Turner (forthcoming). *All participants were required to contribute to the $\mathrm{G}$ (government bond) fund. 
Table II.B.6: Expected Difference in Retiree Pension Assets by Sex Resulting from Different Allocation of Pension Contributions to Stock over the Worklife

Years in the Plan

10

20

30

35
Male/Female Portfolio Size

1.04

1.08

1.13

1.16

Source: Source: Hinz and Turner (forthcoming) 
Table II.C.l. Financial Advice Sought by Average Americans

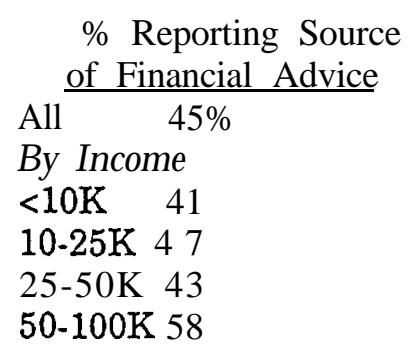

$\%$ Reporting Source

All $45 \%$

By Income

$<10 \mathrm{~K} \quad 41$

50-100K 58

Type of Advice Used Among Those Using

\begin{tabular}{cccccc} 
Friend/ & & & & & \\
Relative & Banker & Broker & Acc't & Tax & Adv. \\
\hline $57 \%$ & 26 & 17 & 14 & 9 & 11
\end{tabular}

$\begin{array}{rrrrrr}64 & 29 & 6 & 6 & 1 & 14 \\ 61 & 27 & 12 & 9 & 5 & 10 \\ 54 & 25 & 19 & 17 & 14 & 8 \\ 39 & 20 & 42 & 34 & 9 & 11\end{array}$

Source: Kennickell et al. (1996) 
Figure II.C.l. - One Year and 30 Year Return Simulations
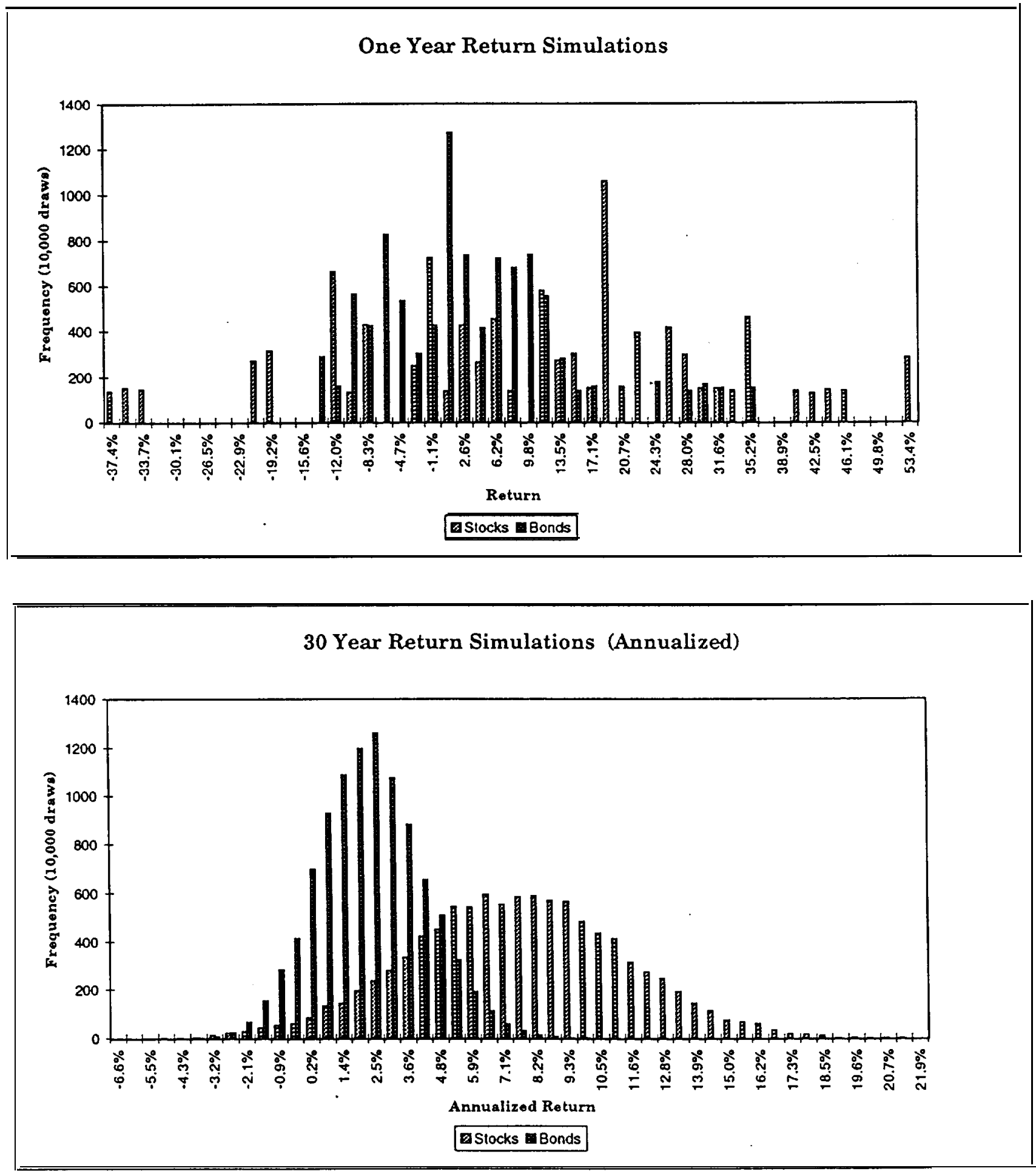

Source: Authors' Calculations 
Table III. B.l Changes in Bequeathable Wealth Among Older US Households

\begin{tabular}{lll} 
Study & $\begin{array}{c}\text { Annual Rate of } \\
\text { Wealth Change }\end{array}$ & $\begin{array}{l}\text { Dataset } \\
\text { Used in Analvsis }\end{array}$ \\
\hline Summarized in Hurd (1993: T6) & & \\
Mirer (1980) & $-1.2 \%$ & 1963 \& 1964 Federal Reserve data \\
Diamond \& Hausman (1984) & -5.0 & NLS Mature Men \\
Hurd (1987) & -4.5 & Single People, RHS 1969-79 \\
Hurd (1991) & -1.6 & Couples, RHS 1969-79 \\
& -3.9 & Single People, SIPP 1984 \\
& -1.8 & Couples, SIPP 1984
\end{tabular}

Sources: Adapted from Hurd (1993: T. 6), Disney (1996), 
Table III.B.2.: Annual Income From Assets for Typical HRS Household at Age 65 (\$1992)

$$
\begin{aligned}
& \text { Assets Drawn Down } \\
& \text { Using IRS Minimum } \\
& \text { Distribution Tables } \\
& \text { As Guidelines }
\end{aligned}
$$

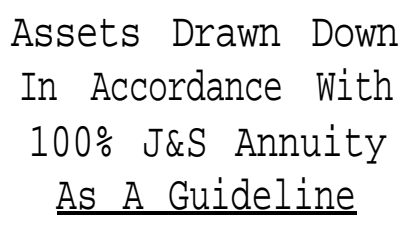

Assuming No Additional Saving

All Assets other than

Social Security*

$\$$

$$
10,800
$$

$\$$

15,400

Net Financial Wealth

Plus Housing

$$
7,000
$$

10,000

Net Financial Wealth

Only

$$
3,900
$$

5,500

\begin{tabular}{lcc} 
Assuming $23.3 \%$ Annual Saving & & \\
\hline $\begin{array}{l}\text { All Assets other than } \\
\text { Social Security* }\end{array}$ & 15,600 & 22,200 \\
$\begin{array}{l}\text { Net Financial Wealth } \\
\text { Plus Housing }\end{array}$ & 11,800 & 16,800 \\
$\begin{array}{l}\text { Net Financial Wealth } \\
\text { Only }\end{array}$ & 8,700 & 12,300 \\
& & \\
Est. Ann. Household SS Benefits & 15,000 &
\end{tabular}

Source: Authors' Calculations .

Notes: * Assumes household has access and control of distribution of Pension Wealth. $100 \%$ J\&S Annuity factor calculated using Social Security mortality tables for males and females born in 1936 and a real interest rate of $2.5 \%$. 
Table III.B.3.: Financial Asset Holdings in the HRS by Bequest Intention

Importance of Bequests

Very Important

Somewhat Important

Not Important

Spouses Differ in Opinion

\begin{tabular}{rrr}
\multicolumn{2}{c}{ Median } & Mean \\
40,400 & $\$$ & 213,350 \\
46,700 & & 178,620 \\
34,800 & 126,657 \\
77,800 & 324,935
\end{tabular}

Expect to Leave Sizable Bequest

Definetly Wii

Probably Will

Possibly Will

Probably Will Not

Definetly Will Not

Source: Authors' calculations
Financial Net Worth

Financial Net Worth

Financial Net Worth + Housing

\begin{tabular}{rr} 
Median & \multicolumn{1}{c}{ Mean } \\
106,700 & $\$ 283,540$ \\
107,000 & 245,594 \\
86,050 & 183,127 \\
164,000 & 430,060
\end{tabular}

Financial Net Worth + Housing

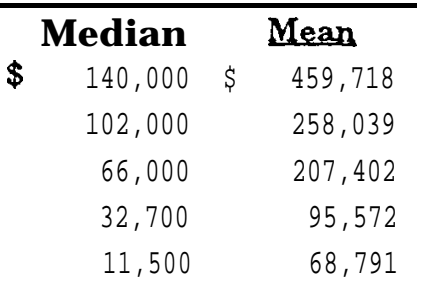

Mean

561,546

354,789

284,197

151,700

106,234

\begin{tabular}{|c|c|}
\hline 240,000 & 561,546 \\
\hline 193,000 & 354,789 \\
\hline 140,000 & 284,197 \\
\hline 85,100 & 151,700 \\
\hline 42,500 & 106,234 \\
\hline
\end{tabular}

